
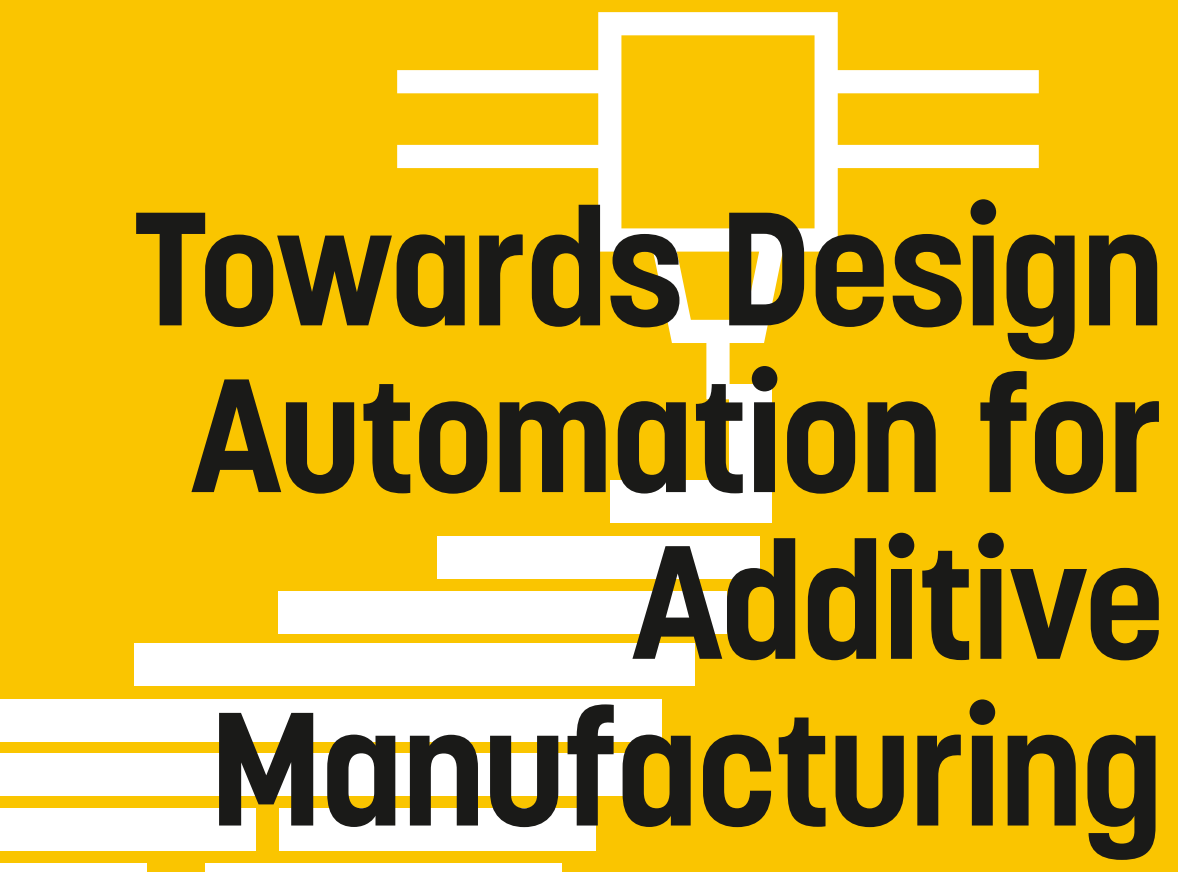
A Multidisciplinary Optimization approach

Anton Wiberg

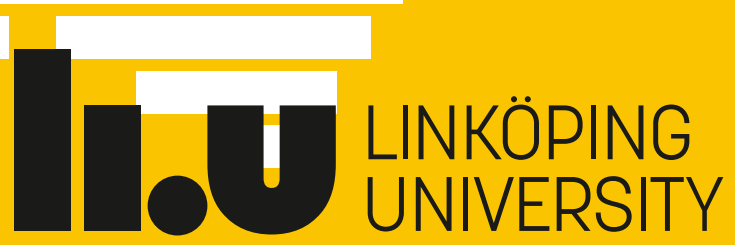




\title{
Towards Design Automation for Additive Manufacturing \\ - A multidisciplinary optimization approach
}

\author{
Anton Wiberg
}

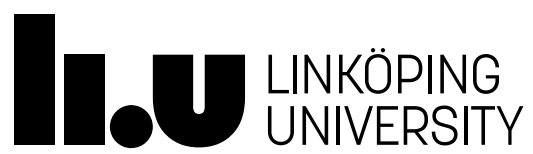

Linköping University

Department of Management and Engineering

Division of Machine Design

SE-581 83 Linköping, Sweden

Linköping 2019 
This is a Swedish Licentiate's Thesis

Swedish postgraduate education leads to a doctor's degree and/or a licentiate's degree. A doctor's degree comprises 240 ECTS credits (4 years of full-time studies). A licentiate's degree comprises 120 ECTS credits.

(C) Anton Wiberg, 2019

ISBN 978-91-7929-985-9

ISSN 0280-7971

Printed by LiU-Tryck, Linköping 2019 


\begin{abstract}
In recent decades, the development of computer-controlled manufacturing by adding material layer by layer, called Additive Manufacturing (AM), has developed at a rapid pace. The technology adds possibilities to the manufacturing of geometries that are not possible, or at least not economically feasible, to manufacture by more conventional manufacturing methods. AM comes with the idea that complexity is free, meaning that complex geometries are as expensive to manufacture as simple geometries. This is partly true, but there remain several design rules that needs to be considered before manufacturing. The research field Design for Additive Manufacturing (DfAM) consists of research that aims to take advantage of the possibilities of AM while considering the limitations of the technique.
\end{abstract}

Computer Aided technologies (CAx) is the name of the usage of methods and software that aim to support a digital product development process. CAx includes software and methods for design, the evaluation of designs, manufacturing support, and other things. The common goal with all CAx disciplines is to achieve better products at a lower cost and with a shorter development time.

The work presented in this thesis bridges DfAM with CAx with the aim of achieving design automation for AM. The work reviews the current DfAM process and proposes a new integrated DfAM process that considers the functionality and manufacturing of components. Selected parts of the proposed process are implemented in a case study in order to evaluate the proposed process. In addition, a tool that supports part of the design process is developed.

The proposed design process implements Multidisciplinary Design Optimization (MDO) with a parametric $\mathrm{CAD}$ model that is evaluated from functional and manufacturing perspectives. In the implementation, a structural component is designed using the MDO framework, which includes Computer Aided Engineering (CAE) models for structural evaluation, the calculation of weight, and how much support material that needs to be added during manufacturing. The component is optimized for the reduction of weight and minimization of support material, while the stress levels in the component are constrained. The developed tool uses methods for high level Parametric CAD modelling to simplify the creation of parametric CAD models based on Topology Optimization (TO) results.

The work concludes that the implementation of CAx technologies in the DfAM process enables a more automated design process with less manual design iterations than traditional DfAM processes. It also discusses and presents directions for further research to achieve a fully automated design process for Additive Manufacturing. 



\section{Acknowledgments}

The work presented in this thesis was performed at the Division of Machine Design, Department of Management and Engineering (IEI) at Linköping University. The work is part of the project AddMan and has received funding from Clean Sky 2 Joint Undertaking under the European Union Research and Innovation programme Horizon 2020 under grant agreement No. 738002.

During the process I received a lot of support and advice from various people, all of whom all have contributed to the work. I am grateful for all the support and would like to express my special gratitude to the following:

I would like to thank my supervisor Professor Johan Ölvander and my co-supervisor Dr. Johan Persson for your support during the work. You have advised and supported me during good times and bad. I would also like to thank my colleagues at Machine Design where several of you contributed to the work through discussions, giving me advice, or answering my sometimes stupid questions.

I would also like to send a thank you to my other collaboration partners within AddMan and especially the people who took care of me during my visit at the MTC.

Last but not least, I would like to thank my family, including Astro, you have done momentous work with your support and by cheering me up when needed.

Anton Wiberg

Linköping, 2019 



\section{Appended papers}

The foundation of the work presented in this thesis is built on the three independent articles that are presented below. The papers are referred to with Roman numerals.

[I] Wiberg A., Persson J., Ölvander J., "Design for Additive Manufacturing: A review of available design methods and software", Rapid Prototyping Journal 2019, Vol. 25 No. 6, pp. 1080-1094.

[II] Wiberg A., Persson J., Ölvander J., "An optimization framework for Additive Manufacturing given Topology Optimisation results", Proceedings of the TMCE 2018, Las Palmas de Gran Canaria, Spain, pp. 533-542.

[III] Wiberg A., Persson J., Ölvander J., "Design for Additive Manufacturing using a Master Model approach", Proceedings of the ASME 2019, International Design Engineering Technical Conferences, and Computers and Information in Engineering Conference IDETC/CIE2019, Anaheim, CA, USA. 


\section{Contents}

1 Introduction 1

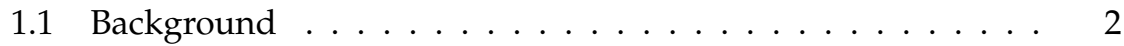

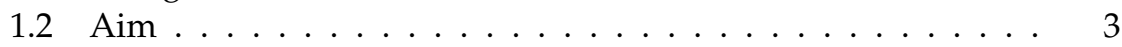

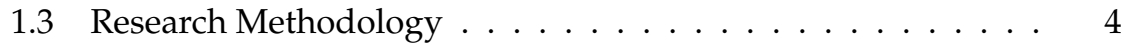

1.4 Outline of the thesis ............... 6

2 Additive Manufacturing 9

2.1 Additive Manufacturing Technologies . . . . . . . . . . . . . . 9

2.2 Design for Additive Manufacturing . . . . . . . . . . . 13

3 Computer Aided Technologies 19

3.1 Computer Aided Design . . . . . . . . . . . . . . . . . . . . . 19

3.2 Knowledge Based Engineering ............. . . . . 22

3.3 Design Optimisation ................. 23

4 Computer Support for DfAM 27

4.1 Paper I - A review of DfAM methodology . . . . . . . . . . . . . 27

4.2 Paper II - A DfAM case study . . . . . . . . . . . . . . . . 29

4.3 Paper III - Development of a tool supporting the DfAM process 34

5 Discussion $\quad 39$

5.1 Research Method Discussion .............. 39

5.2 Results Discussion ................. 39

5.3 The work in a wider context . . . . . . . . . . . . 42

6 Conclusion 43

6.1 Answering the Research Questions . . . . . . . . . . . . . . . . 43

6.2 Outlook........................ 44

$\begin{array}{ll}\text { Bibliography } & 47\end{array}$ 


\section{List of Figures}

1 Overview of the AddMan project. . . . . . . . . . . . . 2

2 The scope covered by the thesis divided into three different levels. 3

3 The Design Research Methodology, and how it relates to the appended papers. ................... 5

4 Overview of the chapters in the thesis. . . . . . . . . 6

5 An overview of AM technologies. . . . . . . . . . . . . . 10

6 Overview of the Powder Bed Fusion manufacturing process. . . . 11

7 A state of the art design process for AM. . . . . . . . . . . . 14

8 Principles for high level parametric CAD modelling. . . . . . . . 21

9 Levels of automation for creation of models within parametric modelling. . . . . . . . . . . . . . . . 22

10 Examples of results from structural optimization. . . . . . . . 25

11 Method used in Paper I. . . . . . . . . . . . . . . . . . . . 28

12 Simulation driven design process for $\mathrm{AM}$, as an enhancement of the state-of-the-art process presented in figure $7 \ldots \ldots$. . . . . . . . . 29

13 Method used in Paper II. . . . . . . . . . . . . . . . . . . . . . . 30

14 Example of the method used for creation of the parametric CAD model. . . . . . . . . . . . . . . . . . 31

15 A distributed multidisciplinary optimisation framework for AM. 31

16 A monolithic multidisciplinary optimisation framework for AM. 31

17 Results Paper II. . . . . . . . . . . . . . . . . . . . . . . . . . 33

18 Method used in Paper III. . . . . . . . . . . . . . . . . . . . 35

19 Format of the objects used to save different kind of information. . 36

20 Interface of tool developed in Paper III. . . . . . . . . . . . . . 38

21 Example of geometry created by the tool developed in Paper III. . 38 



\title{
List of Abbreviations
}

\author{
AM Additive Manufacturing \\ CAD Computer Aided Design \\ CAE Computer Aided Engineering \\ CAx Computer Aided Technologies \\ DA Design Automation \\ DfAM Design for Additive Manufacturing \\ DOE Design of Experiments \\ DRM Design Research Methodology \\ EBM Electron Beam Manufacturing \\ FEA Finite Element Analysis \\ GA Genetic Algorithms \\ KBE Knowledge Based Engineering \\ LBM Laser Beam Manufacturing \\ MDO Multidisciplinary Design Optimization \\ PBF Powder Bed Fusion \\ PDP Product Development Process \\ TO Topology Optimisation \\ UTS Ultimate Tensile Strength \\ YS Yield Strength
}





\section{Introduction}

One way of dividing manufacturing is into the three categories Subtractive, Forming, and Additive manufacturing [28]. In subtractive manufacturing, a larger part of material is split into a desired shape with cutting, milling, tearing, or other methods. Subtractive manufacturing was first used to create tools out of wood or stone. Later humans learned to handle metals such as gold and copper. These were manufactured using a combination of subtractive and forming techniques. In forming manufacturing, material is rearranged to the desired shape with mechanical, thermal or chemical forces. These two manufacturing categories have been used for thousands of years. Over the years more types of materials were used, and the methods were refined for the creation of more complex shapes with higher precision and at a lower cost [25].

In the 1980s, a new paradigm in manufacturing began with several patents that focused on how 3D objects could be created by selectively adding material in a systematized way [19]. After several years with different names, such as 3D printing, rapid prototyping, and rapid manufacturing, the standardization organizations ISO and ASTM came with the first standard in 2013. The standard states that the term Additive Manufacturing (AM) should be used to describe the action of "joining materials to make parts from 3D model data, usually layer upon layer" [28]. It could be discussed if techniques such as knitting, painting, or welding should be included in AM, and the manufacturing technique therefore is much older. This philosophical discussion is however seen as out of the scope of this thesis.

The last 10-20 years have resulted in large steps in the development of the AM manufacturing process with several variants of the technique, many new materials that are possible to process, higher quality of the manufactured parts, and an increased market of cheap machines. Three advantages of using AM compared to other manufacturing techniques are: the possibility of creating individualized design without adding cost; the possibility of 
creating complex structures with integrated functionality; and the possibility of creating lighter structures [34]. All of these advantages put high demand on the design process. While the development of the manufacturing processes has gone very fast, knowledge about how to design parts for AM has not seen the same development. As stated by Simpson [54] today's design workflows and software tools do not harmonize well in a Design for Additive Manufacturing (DfAM) process.

\subsection{Background}

The research in this thesis is part of the project AddMan [57], which aims to gain knowledge that brings AM to practical use in the aeronautic area. This includes work on material characterization, the development of design tools and methods, and the development of post processing strategies. The goal with AddMan is to develop an environment where design tools and methods co-operate with CAE tools and AM knowledge and can be used when designing components. An overview of this basic idea is shown in figure 1.

The focus of the research project is on structural components manufactured in metal with the Powder-Bed-Fusion (PBF) AM technique (described in chapter 2). The developed methods and tools should, however, be general and applicable to components manufactured in other materials and with other AM techniques.

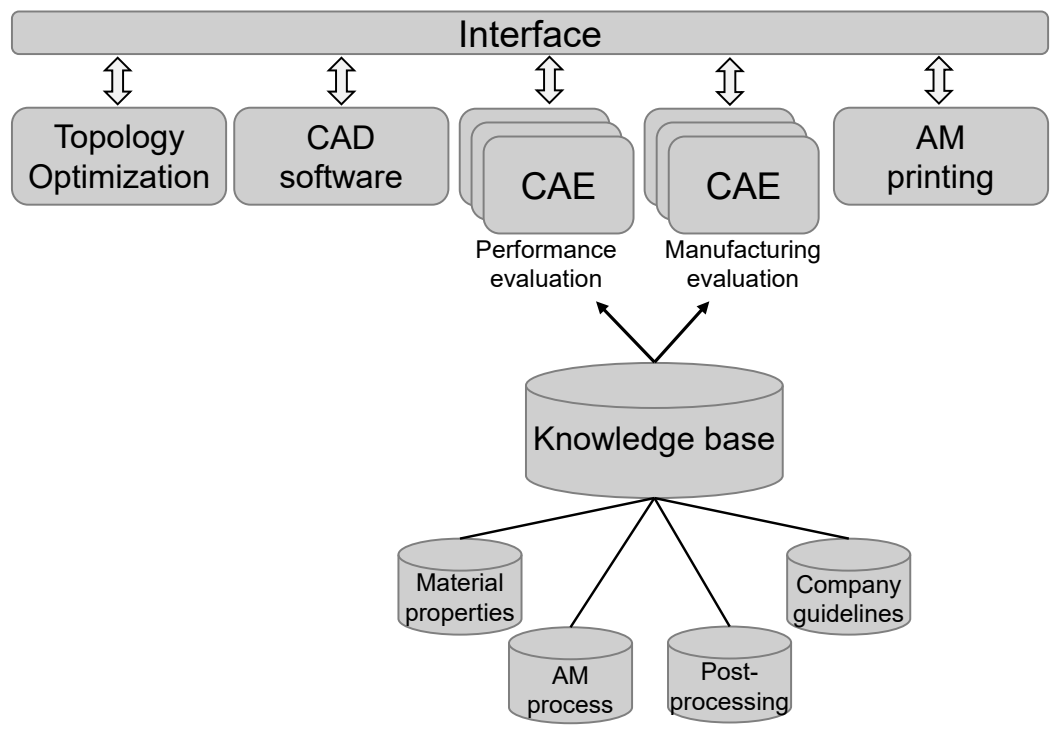

Figure 1: Overview of the idea behind the AddMan project [57]. 
In this thesis, Design Automation (DA) is defined as the use of computer technologies in order to automate as many of the repetitive tasks in the design process as possible. DA not only reduces the time and effort needed to design components, but it also has the potential to decrease the risk of human error. Since manual effort in the design process is reduced, DA creates the possibility for the creation of customized products. An optimization-driven DA process also has potential to increase the efficiency of products [31]. The advantages of using DA correspond well with the manufacturing possibilities coupled to AM.

Computer Aided technologies (CAx) is a term that describes the use of different design, analysis, and manufacturing tools to aid digital product development. These technologies are used in order to gain knowledge early in the Product Development Process (PDP) with the goal of achieving a shorter development process while creating better products. The work presented in this thesis is focused on the interaction between different CAx disciplines used to design products manufactured using AM. As seen in the AddMan overview in figure 1, this includes different methods and tools for optimization, design, and performance and manufacturing analysis. It also includes the capturing and use of knowledge for AM compiled within the research project.

\subsection{Aim}

The aim of the research is to analyze existing DfAM knowledge and to create and evaluate new methods and tools for DfAM. The work was conducted on three different levels: first on a methodology level with a focus on general design methods; then on a tool level with a focus on the development of computer solutions to support the methodology level; and finally on an application level focused on the evaluation of the methods and tools in different case studies. An overview of the three implementation levels is shown in figure 2.

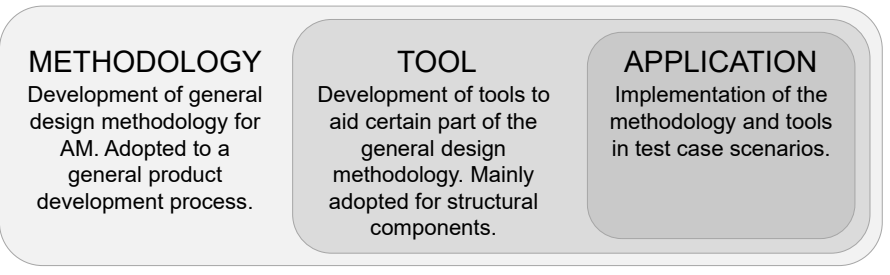

Figure 2: The scope covered by the thesis divided into three different levels.

In order to narrow the aim of the work, three research questions were formulated. The questions point out the direction of the research and are, therefore, formulated in an open-ended way. This gives the possibility for 
broad answers based on the work performed. Together with the scope, presented in figure 2 , the research questions provide an overview for the reader to understand the context of the work. The research questions are stated below:

1. What is the state of the art when it comes to DfAM?

2. How can a higher degree of design automation in the DfAM process be achieved?

3. How can design tools that support a future DfAM process be structured?

\subsection{Research Methodology}

The overall research followed the Design Research Methodology (DRM) presented by Blessing and Chakrabarti [11]. DRM is tailor-made for engineering design research and aims to find solutions for immediate problems that society or industry face. The DRM method consists of four steps that are performed in an iterative way until the desired result is achieved, see figure 3. The four steps are:

- Research Clarification (RC): Build evidence or at least find indications that the research field is valid, and the research goal is specified.

- Description Study I (DS-I): Identify the main challenges in the research and determine which factors the continuing research should focus on.

- Prescriptive Study (PS): Development of support that will aid future work and help to overcome the gap identified in DS-I. The developed support could be in the form of software, algorithms, or other tools that aid the design process.

- Description Study II (DS-II): Evaluation of the developed support compared to the research goal.

The steps in the DRM process are reflected in the three separate studies where the means and goals of the studies are similar to what is proposed in the DRM. How the work and the appended papers relate to the Design Research Methodology is visualized in figure 3. 


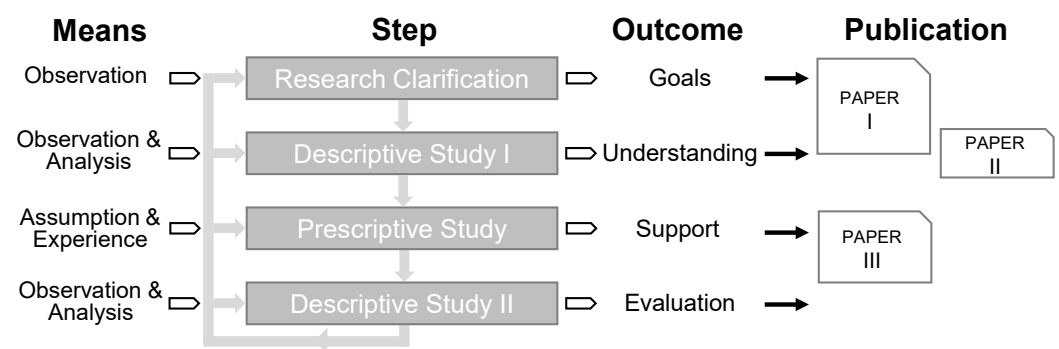

Figure 3: The Design Research Methodology, and how it relates to the appended papers, after [11].

Paper I consists of a literature review that examines and analyzes today's DfAM process. This correlates to the Research Clarification step where the paper, in addition to a review of existing research, also proposes a DfAM process that uses a higher degree of design automation. This proposed designed process was used as a guide during the research work. The analyses performed during the work with Paper I also cover part of DS-I. The review performed in this study follows a structured methodology, which is presented together with the result of the review in section 4.1.

In Paper II, the main design automation idea proposed in Paper I is implemented in a case study in order to understand the proposed design process. In practice, the study used existing tools, reduced complexity, and required more manual work than what is proposed in Paper I. The work corresponds to DS-I, where the goal is to verify the feasibility and understand the proposed process. The methodology used during the work in Paper II is presented in section 4.2.

Paper III presents and showcases a solution for the support of part of the proposed DfAM process. The support is presented as a generic method, but it is also implemented in a tool. The tool is evaluated in an application on a component. The work, therefore, corresponds mostly to the PS step of the Design Research Methodology, but it also performs a minor evaluation and, therefore, touches on the DS-II step.

The content of the three papers can also be coupled to the three research levels Methodology, Tool, and Application (see figure 2). The main contribution to the Methodology level is the proposed DfAM process presented in Paper I, but Paper III also contributes to this process with a more detailed methodology for part of the design process. The tool developed in Paper III contributes to the Tool level, and the case studies in Papers II and III contribute to the Application level of the research. The methodology applied during the research process is based on a deductive research approach [4] where a theory is collected, based on the theory a hypothesis is formed at the Methodology level and the Tool level verify that the proposed method 
technically can be realized. Finally the Application research level creates evidence for the Tool level.

\subsection{Outline of the thesis}

This thesis is divided into six chapters; Introduction; Additive Manufacturing; Computer Aided Technologies; Computer Support for DfAM; Discussion; and Conclusions, see figure 4 . As the thesis is a compilation of the work presented in the appended papers the different chapters aim to further describe the background of the work and how the appended papers relate to each other. The first chapter, Introduction, provides the reader with the background of the performed work and shows the direction of the research. The second chapter, Additive Manufacturing, combines information about Additive Manufacturing processes and materials with a complied state-of-the-art DfAM process. The DfAM process is one of the results of Paper I, and hence, the chapter can be seen as a combination of theory and a contribution of the thesis. Chapter three, Computer Aided Technologies, contains the theory from the CAx area that was used as a base for the technical implementations of the proposed DfAM process in Papers II and III. In the fourth chapter, Computer Support for $D f A M$, the proposed design method, its contribution, and conclusions from the three appended papers are presented. Chapters five and six discuss and conclude the thesis.

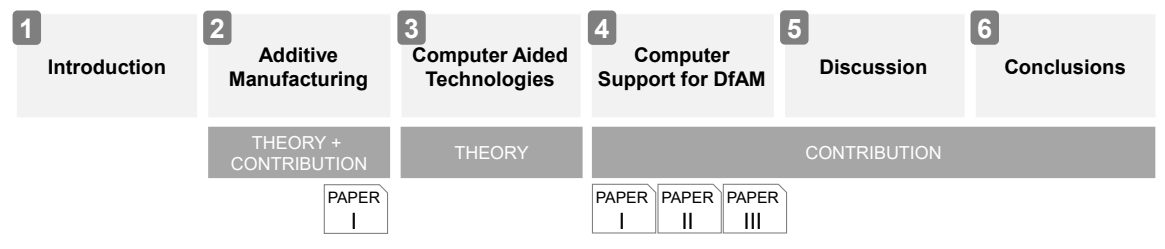

Figure 4: Overview of the chapters in the thesis.

A short description of the content of each chapter is presented below:

- Chapter 1: Introduction to the performed work with background, aim, and research method.

- Chapter 2: Compilation of existing knowledge in the area of AM and DfAM. Contribution with a compilation of a state-of-the-art design process for AM.

- Chapter 3: Theoretical background of different Computer Aided Technologies and their possibilities.

- Chapter 4: Presentation of the appended papers with the aim of bridging AM and CAx in order to expand the current design for AM possibilities. 
- Chapter 5: Discussion of the research method used, the strengths and weaknesses of the results, and the work in a larger context.

- Chapter 6: Conclusions of the work with answers to the research questions. 



\section{Additive Manufacturing}

The theory about AM is divided into two sections. In section 2.1, AM is presented from a manufacturing perspective with an overview of AM technologies and materials. Since the project is focused on metal manufacturing using the Powder Bed Fusion (PBF) techniques, this AM category is explained in more detail. Section 2.2 focuses on Design for Additive Manufacturing. This section is based on the review of current research, which is presented in Paper I.

\subsection{Additive Manufacturing Technologies}

$\mathrm{AM}$ is defined as the process of the creation of parts by successively adding material, which is often made in a layer-by-layer approach [28]. AM is not one manufacturing process, instead it could be divided into seven different categories where each category is divided into several manufacturing techniques. The seven AM categories are: Vat Photopolymerization, Material Extrusion, Material Jetting, Binder Jetting, Powder Bed Fusion, Direct Energy Deposition, and Sheet Lamination [18].

As the name implies, Vat Photopolymerization uses a photopolymerization reaction to solidify liquids, resins, or photopolymers. Material Extrusion works by pressing semi-solid material through a nozzle. It is necessary for the material to solidify while keeping the shape from the nozzle. Material Jetting has its origins in the 2D Inkjet printing technique and is a combination of photopolymerization and material extrusion. The build platform and movement are similar to material extrusion, but instead of pressing a material through a nozzle, droplets of material are applied. The droplets are directly fabricated using photopolymerization. Powder Bed Fusion (PBF) is a technique where material powder is distributed in a build chamber. The material is selectively fabricated with an energy source during a sintering or melting process. Direct Energy Deposition is somewhat similar, but in- stead 
of adding powder successively in layers within a build chamber, the material (in powder or wire form) is added directly to the component through some kind of nozzle. Binder Jetting is a powder bed technique similar to PBF, but instead of using a heat source to fabricate the object, a binder is applied to the powder in order to form objects. The last AM category is Sheet Lamination. In this method, sheets of materials are added and cut into cross-sections of the desired geometry [19].

An overview of the AM categories together with a description of the pros and cons of the categories, and some of the available techniques and materials, are shown in figure 5 .

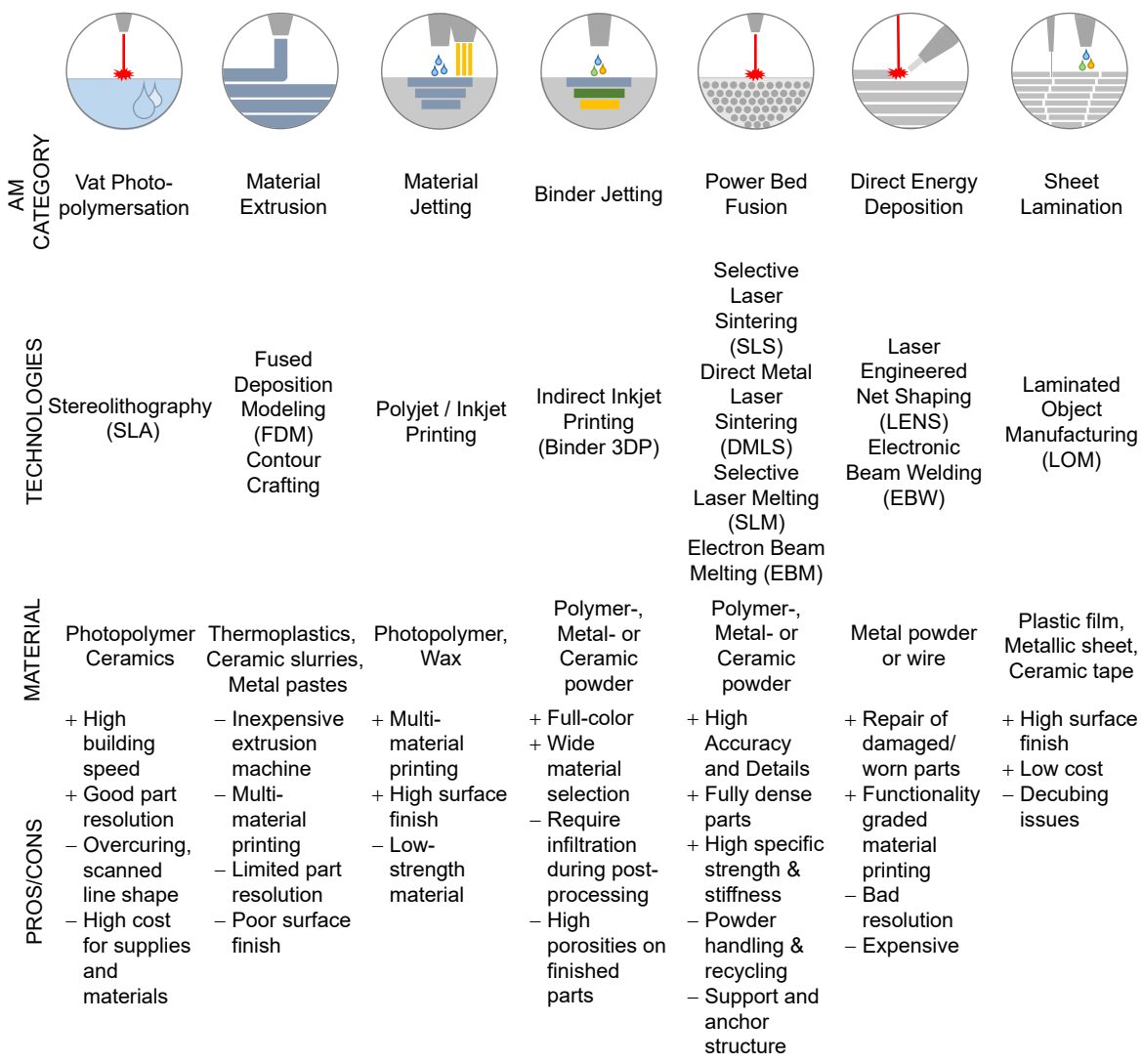

Figure 5: An overview of AM technologies, adapted from [18].

\section{Powder Bed Fusion}

The focus of the AddMan research project is metal components manufactured using Powder Bed Fusion. Similar to most AM techniques, Powder Bed Fusion uses a layer-by-layer by approach to manufacture components. 
The virtual 3D representation of the component is split into layers where the layers of the component are manufactured as $2 \mathrm{D}$ sections that are built on each other. In PBF, a thin layer of material powder is distributed over a build platform with a scraper or a roller. A section of the component is then selectively sintered or melted using an energy system in the form of a laseror an electron-beam. During the heating, the material fuses before it cools, and the build platform is lowered a small step before the sequence starts over in the next layer. The manufacturing on one layer is often referred to as manufacturing on the XY-plane, while the build direction is referred to as the Z-axis. The distance the platform moves in height between each layer is referred to as layer height [19]. As non-manufactured powder surrounds the component, it gives the component support so that it does not collapse due to gravitation. Depending on which material and machine are used, high temperatures may lead to stresses or dislocation in the material. These require the manufacture of extra material (called support material) to prevent the AM build from failing. The manufacturing is normally performed inside an enclosed build chamber where the chemical composition and temperature of the atmosphere are carefully controlled [19]. An overview of a simple PBF system is shown in figure 6.

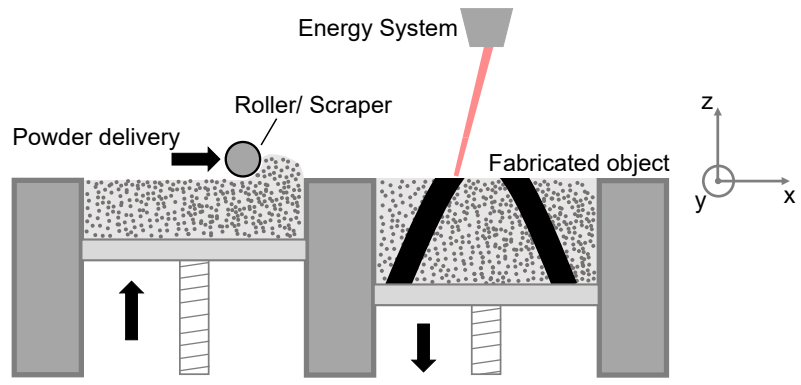

Figure 6: Overview of the Powder Bed Fusion manufacturing process.

Distributors of PBF machines use different names and acronyms for the technique in their PBF process. Some of the best known are Selective Laser Sintering (SLS), Selective Laser Melting (SLM), Direct Metal Laser Sintering (DMLS), and Electron Beam Melting (EBM). Depending on which machine has been chosen using these techniques, there are variations in the size of build chamber, number of energy sources used, material available, and other parameters which effect the manufacturing restraints and time.

These techniques can be divided based on whether a laser or electron beam is used as the energy source. These will be referred to as Laser Beam Manufacturing (LBM) and Electron Beam Manufacturing (EBM) hereinafter. A comparison between some of the manufacturing characteristics for these two processes are shown in table 1 . 
Table 1: A comparison between some manufacturing features for LBM and EBM.

\begin{tabular}{|c|c|c|}
\cline { 2 - 3 } \multicolumn{1}{c|}{} & EBM & LBM \\
\hline Powder size & $45-100 \mu \mathrm{m} \mathrm{[21]}$ & $25-45 \mu \mathrm{m}[21]$ \\
\hline Spot size & $\sim 0.1 \mathrm{~mm} \mathrm{[22]}$ & $\sim 0.01 \mathrm{~mm} \mathrm{[42]}$ \\
\hline Layer height & $50-100 \mu \mathrm{m}[43]$ & $20-100 \mu \mathrm{m} \mathrm{[23]}$ \\
\hline Build temp & $\sim 0.8^{*}$ melt temperature [42] & $\sim 90^{\circ} \mathrm{C}[42]$ \\
\hline Build atmosphere & Vacuum [42] & Argon or Nitrogen [42] \\
\hline
\end{tabular}

While LBM transfers heat into a powder, EBM heats the powder bed with kinetic energy from the accelerated electrons. The collation between the powder bed and the electrons can result in a cloud of powder. This is the reason the powder used for EBM is larger than the one used for LBM. As a consequence of the higher energy input into the powder bed by the electron beam, the spot size and layer height are also larger. Both the risk of powder clouds and the higher energy input of the electron beam explain why the temperature of the whole build needs to be higher for EBM than for LBM. By heating the whole build volume to around $80 \%$ of the melting temperature, all the material inside the build chamber is sintered, which reduces the risk of powder clouds during manufacturing. With a heating powder surrounding the manufactured areas, a steady state environment is formed, which reduces the risk of thermal stress, which, in turn, could lead to deformation in the build [19].

The most revealing effect on geometrical constraints is that LBM can manufacture smaller details and inner structures that are not possible with EBM. On the other hand, the larger energy input, spot size, and layer height used with the electron beam enables faster manufacturing. The more homogeneous temperature and properties of the build volume in EBM also creates the potential to pack components on top of each other within the same build, which is not possible with LBM. However, the total build time is quite similar for EBM and LBM because of the preparation time required for EBM when vacuum is to be created and the build volume is to be heated [19].

The mechanical properties of metals manufactured with PBF are comparable to wrought material. The static properties in terms of Yield Strength (YS) and Ultimate Tensile Strength (UTS) are relatively similar among materials manufactured with LBM and EBM. EBM shows more homogeneous properties, while LBM has better properties in the build direction than within a layer [17]. When it comes to fatigue properties, metals from PBF show significantly worse properties than wrought material. EBM shows both worse surface roughness and fatigue behavior than LBM- manufactured components [32]. An overview of static material properties for LBM- and EBM manufactured Ti-6Al-4V is presented in table 2. 
Table 2: Material properties for Ti-6Al-4V manufacture by PBF, adapted from [17].

\begin{tabular}{|c|c|c|c|c|}
\cline { 2 - 5 } \multicolumn{1}{c|}{} & \multicolumn{2}{c|}{ EBM } & \multicolumn{2}{c|}{ LBM } \\
\hline Orientation & XY & Z & XY & Z \\
\hline YS $(\mathrm{MPa})$ & 848 & 841 & 887 & 946 \\
\hline UTS $(\mathrm{MPa})$ & 946 & 946 & 997 & 1010 \\
\hline $\begin{array}{c}\text { Surface } \\
\text { roughness }(\mathrm{Ra})\end{array}$ & Top: $\sim 199$ & Side: $\sim 594$ & Top: $\sim 124$ & Side: $\sim 318$ \\
\hline
\end{tabular}

\subsection{Design for Additive Manufacturing}

Design for Additive Manufacturing (DfAM) has its origins in the research field Design for Manufacturing (DFM). Anderson [5] defines DFM as design of a product while the manufacturing, testing, assembly, service, repair, and cost are optimized. At the same time, the safety, time-to-market, functionality, and styling are not to be compromised.

Exactly how this is translated into DfAM is not standardized. Instead, there are several different approaches to defining and splitting up current research. These approaches include everything from how to choose which parts are suitable for AM, to how to best calibrate the AM machine. However, two different divisions of research into DfAM have been presented by Thompson et al. [61] and by Rosen [49]. Thompson divides the area of DfAM into the following levels: Part level with macro-scale complexity; Material level with micro scale complexity; and Product level with multi-scale complexity. In contrast to Rosen who divides DfAM into the three sub categories: Process Design; Materials Design; and Part/Product Design. These categories resemble the ones proposed by Thompson, but the Material level in Thompson's research is split based on whether the process time and cost or the material are affected. Instead, the Part and Product levels are included in one category.

In Paper I, a DfAM categorization inspired by the ones from Thompson [61] and Rosen [49] is presented. The categorization focuses on the role of the design engineers in the design process, and it consists of three levels: System design; Part design; and Process design. The levels are to be seen as three stages of the design process. The System design level contains research that supports the selection of components suitable for manufacturing with AM and design on an overall product level. Part design contains research that supports the design of single components. The research within the Process design level is coupled to the manufacturing process, including manufacturing simulation, machine parameter settings, cost modelling, and other choices that influence the manufacturing process. 
With the three design levels as a base, different design activities form a state-of-the-art DfAM process, presented in Paper I. The activities are taken from current research in the field, which includes both overall design methods and tools, and research in specific areas. Examples of publications that present overall design methods with similar steps are Salonitis and Zarban [51], Orquera et al. [44], and Ponche et al [46]. The proposed design levels and activities are presented in figure 7. The arrows back to earlier activities show where changes can be made if the analyses within the activity does not meet the identified demands.

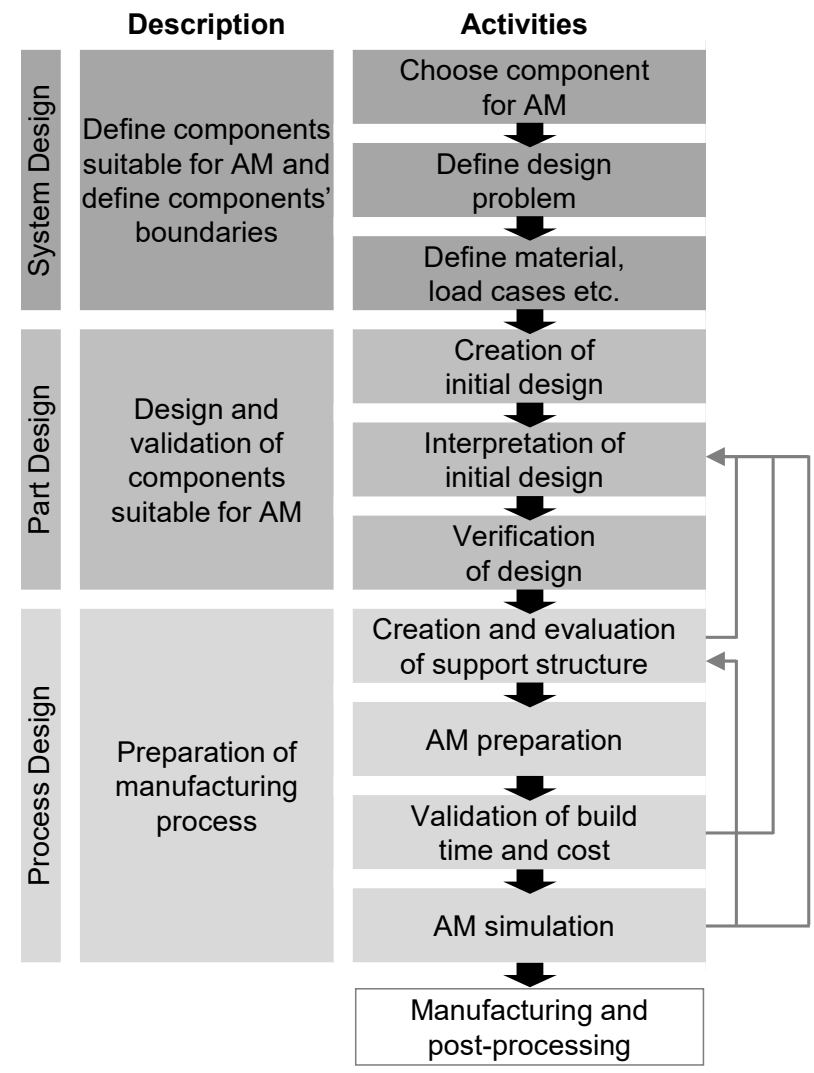

Figure 7: Design levels and activities which together form a state of the art design process for AM.

\section{System Design}

The activities on the System Design level identify the parts suitable for manufacturing with AM and define the design problem. Klahn et al. [35] state that AM can be used as a manufacturing method either as an initial manufac- 
turing method that is later changed for another final manufacturing method when production volumes increase or the product matures, or as a permanent manufacturing solution. The usage of AM as an initial solution for manufacturing makes it possible to start with a low quantity of products and enables easy changes to the product based on early customer feedback, much like prototyping. On the other hand, if AM is chosen as a permanent manufacturing solution, it creates the potential to create products with complex shapes, compared to conventional manufacturing. This potential includes parts with integrated functionality and lightweight structures [34]. These advantages of AM have the potential to add economic, ecological, or experience value to the product [27].

Defining the design problem is about defining boundaries between parts in a product. In most cases, it is proposed to reduce the number of parts within an assembly in order to exploit the AM advantage of integrated functionality and to reduce the cost of assembly. Different approaches to doing this are proposed in current research where Rodrigue and Rivette [48] propose a method supporting the reduction of parts in an existing assembly. Orquere et al. [44] propose a more optimization-driven approach where kinematic and mechanical analyses are performed on simple representations of the products in order to identify part boundaries. Also Bin Maidin [39] proposes a simulation-driven approach where a database with different design features that take advantage of AM possibilities is combined once the boundaries have been defined.

The final step in the System Design phase is the material selection part. In $\mathrm{AM}$, the choice of material is tightly connected to which AM techniques and machines that are available [18]. Most material manufactured with AM is anisotropic, which means that mechanical properties are dependent on both the design of the part and the manufacturing process. Thomas [60] discusses the connection between surface roughness, material properties, geometry, and manufacturing for laser PBF. Yang and Zhao [64] discuss the connection between functional requirements, product breakdown, and material selection. A more detailed description of the System design phase is given in Paper I.

\section{Part Design}

When a product is decomposed into parts, the activities on the Part Design level are intended to design a single part in order to fully exploit the advantages of AM. For structural components, the most frequently used method for the creation of initial designs is Topology Optimization (TO). In recent years, several publications have focused on how TO formulations can be adapted to create designs suitable for manufacturing with AM [38]. Direct usage of results from $\mathrm{TO}$ is, however, in most cases, not possible, and some kind of modification is necessary $[65,59]$. For components with a purpose 
other than structural different ideation methods that support the process of creating innovative solutions have been proposed. Different methods that use design cards or databases with innovative design solutions have been proposed to support this process [39, 10, 12].

While the creation of initial design aims to use different methods to create a concept, the interpretation of the initial design is to create a geometry that fulfils both manufacturing and functional requirements. A compilation of design rules for AM that explain what is preferable to manufacture and what is not is presented by Lammers et al. [36]. In addition to design rules for normal geometries, AM also makes it possible to manufacture different types of lattice structures. Two different methods for the creation of lattice structures is presented by Zhang et al. [66]. The creation of lattice structures is a popular topic in research, such as $[58,8]$. The practical work of creating the design is mainly focused on the usage of traditional CAD software. However, when it comes to the design of lattice structures, software such as Netfabb [7] and Materialise [40] (and others) can support the process.

The verification of design in this step is focused on the verification of functional requirements, including for example structural calculations and other analyses. This activity is not AM-specific and regular Computer Aided Engineering (CAE) analysis is required. What adds complexity to simulations of AM materials is the anisotropic material behavior and the surface roughness, which is dependent on build direction and the geometry of the part.

\section{Process Design}

Once a part has been adapted for AM using design rules and verified for functional requirements, the activities on the process design level are to prepare and verify the manufacturing of components. Since most metal AM techniques require some sort of support structure to prevent deformation during manufacturing, the first activity is to add support structures to the build. A review of different types of support structures and when they are necessary is presented by Jiang et al. [30].

The second activity of process design is AM preparation. An AM preparation consists of the setup of various manufacturing-related choices and activities, such as layer height, slicing of geometry, settings for path planning, and choice of machine parameters. All manufacturing settings are coupled to each other, and the settings can have a major influence on the manufacturing result [84]. The settings that are possible to change depends on the choice of machine and material used.

Based on the machine, geometry, material, and number of parts manufactured in the same build, the third process design step is to calculate the build time and cost of the component. Several different cost models for AM 
exist. Costabile et al. [19] present a review of current approaches to cost calculations for AM products.

The fourth and final activity on the process design level is AM simulation. In this step, the manufacturability of the component is verified by performing a simulation of the manufacturing process. The simulation can be based on physical laws, empirical tests, or a combination of these two [9].

Different commercial software support one or several activities on the process design level. Examples of software are Netfabb [7], Materilise [40], Siemens NX [52], Simplify 3D [53], 3Dsim [1], and Simufact Additive [41]. 



\section{Computer Aided Technologies}

Computer Aided Technologies (CAx) is an umbrella term for the usage of computer-based methods and software to aid design, analysis, and manufacturing of components [15]. The introduction of CAx enables a simulationdriven Product Development Process (PDP). A simulation-driven PDP increases knowledge of a product early in the development process and, thereby, overcomes the product development paradox. The paradox states that, in the beginning of a project, the knowledge of a product is low, but the freedom to make changes is great. Later in the project, knowledge of the product is, instead, large, but the cost of making changes is high [33]. If this can be overcome, the development time and cost of new products can be decreased.

This chapter presents the theories in three different CAx fields, which in different ways, contribute to the research herein. Section 3.1 presents the theory of Computer Aided Design (CAD). CAD is central to the development of new physical products. The second section, Knowledge Based Engineering $(\mathrm{KBE})$, presents theory about how knowledge can be automatically saved and used during a simulation-driven design process. KBE in combination with CAD is one of the main enablers for design automation. The third and last area that is discussed in this chapter is design optimization. The addition of design optimization to $\mathrm{CAD}$ and $\mathrm{KBE}$ not only enables the automatic creation of designs but also the creation of optimal designs.

\subsection{Computer Aided Design}

$\mathrm{CAD}$ is one of the central technologies in modern product development. A CAD model contains geometrical information on a product and can be used as visualization, as a base for computer-based simulations and the evaluation of product properties, and as a base for manufacturing. Depending on how the CAD model is to be used, the geometrical representation is performed in 
different ways. An ideal CAD model in product development should be able to perform all of the above but also be easy to change and update based on feedback from manufacturing, functional evaluation, aesthetics, or other.

This section is divided into two sub-sections. First the background and theory of CAD in relation to AM are presented. This is followed by the theory of parametric CAD.

\section{CAD for Additive Manufacturing}

AM preparation is traditionally done in separate software that reads one or more geometries, places them in a build chamber, and prepares all manufacturing steps with the addition of support material, slicing and path planning, the control of settings, and the creation of g-code [19]. Historically, the STL file format has been used for AM preparation software. STL is a simple format built on tessellation of the geometry where three points build up triangles representing the surface of the geometry. The advantage of the STL format is that it is easy to read and to perform mathematical operations on. However, it also has several disadvantages where the biggest is that the representation of the geometry is approximate since the triangles are flat and do not take care of curvatures in the geometry. By reducing the triangle size, the accuracy can be increased, but this means a larger file size [24]. Other disadvantages with the use of STL files are the risk of errors with holes in the geometry and the difficulty of changing the geometry.

Two file formats, AMF by ISO/ASTM [29] and 3MF by the 3MF consortium [2], have been developed in attempts to overcome some of the disadvantages of STL. These both contain more information than an STL file, such as lattice representation, material, color, texture, build direction, and support structure. These two formats can also describe curvature and, thereby, perform a mathematically correct representation of the geometry. The STL, $\mathrm{AMF}$, and $3 \mathrm{MF}$ file formats are adapted for usage during manufacturing preparation and not during creation and changes to the geometry. Therefore, other formats are needed during the design process.

\section{Parametric CAD modelling}

An essential component to achieve design automation is a geometrical representation that can easily be adapted to desired changes. A way to overcome this difficulty is the usage of parametric CAD models that are controlled by a set of parameters. Parametric CAD modelling can be split into two parts, morphological and topological modelling. Morphological parametric CAD modelling allows easy changes to lengths, radius, widths, positions of splines, and other existing geometrical features. Topological parametric CAD modelling, on the other hand, controls the addition and subtraction of 
features. The topological changes are enabled by High Level CAD templates (HLCt), which are predefined groups of CAD features [3].

CAD software can be compared to a pile of LEGO bricks where functions for the creation of different geometries are integrated, but no instructions for how they are to be used are integrated. Morphological CAD changes are like changing the size or color of a single LEGO brick. While topological changes are similar to adding or removing different bricks, HLCt are like simple structures put together with a couple of bricks. These can, then, be combined in order to create more advanced structures. The combination of morphological and topological parametric modelling can be used in order to create advanced structures that are still easy to change. An overview of the principles of parametric CAD modelling is shown in figure 8 .

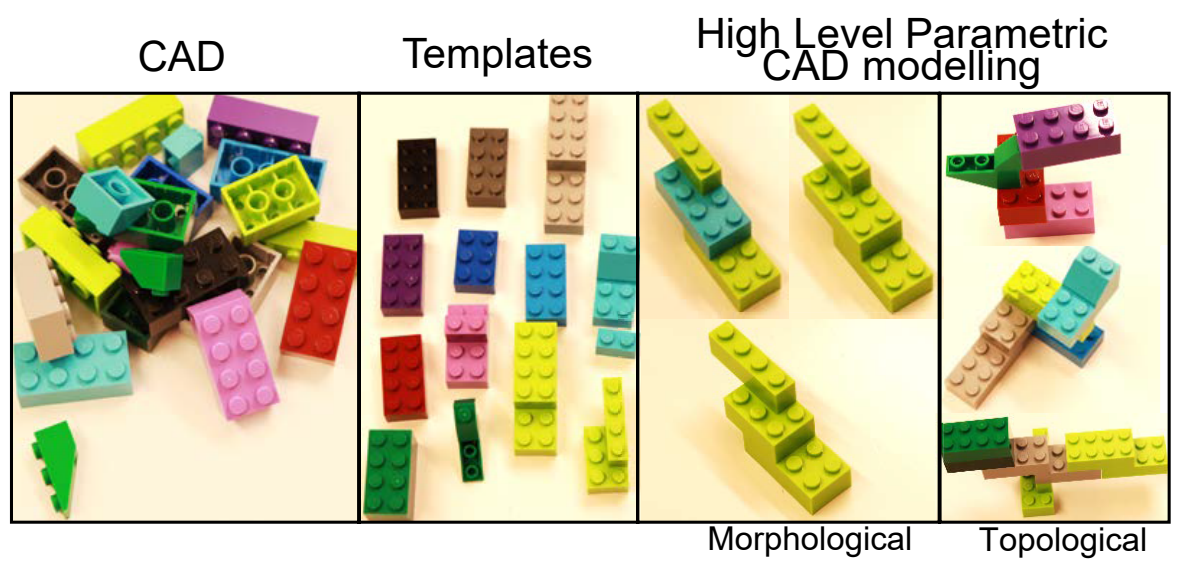

Figure 8: Principles for high level parametric CAD modelling.

The morphological and topological changes can also be split into levels, depending on how the changes are implemented. Morphological changes can be controlled by simple parameters, relations, or scripts. Topological changes can be made by just copying one object multiple times or by instantiating objects with the same base but where changes to the object are made for each copy [3]. An illustration of these stages is presented in figure 9.

In order for a parametric CAD model to be useful for fast changes during product development, it not only needs to be flexible but also robust in order to not fail to update when changes are applied [3]. Xu [63] compares this to building a house of cards; if the foundation is not well built, it will collapse. In order to achieve such a model, it is recommended to use a structured modelling approach [50]. One approach easy to understand and use is the resilient modelling approach [13]. The resilient modelling approach consists of six groups of features in a hierarchy where the features in each group add complexity to the model. It is not allowed to create a feature from a lower hierarchical group based on references from features higher in the hier- 


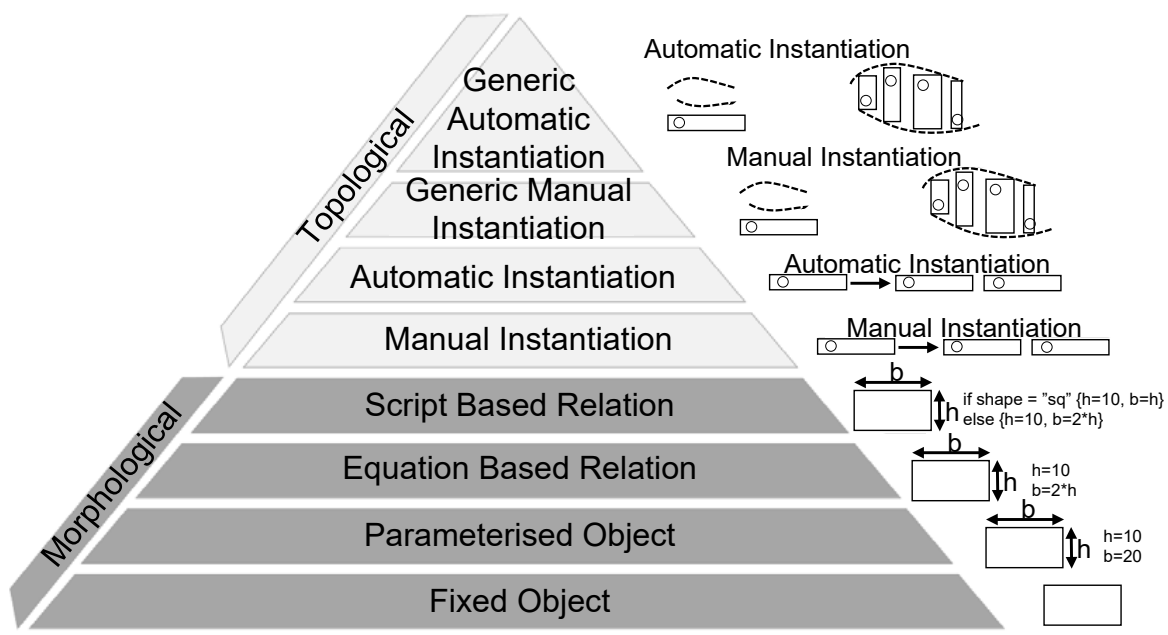

Figure 9: Levels of automation for creation of models within parametric modelling, after [3].

archy. The different groups of features are presented in paper III, the resilient modelling strategy is used as support for the decomposition of geometries in order to create a hierarchy of CAD features within CAD templates.

\subsection{Knowledge Based Engineering}

Knowledge Based Engineering (KBE) is an area that tries to bridge the gap between engineering design, artificial intelligence, and programming. $\mathrm{La}$ Rocca [47] defines KBE as a collection of methods and software to support the capture and reuse of knowledge during the product development process with the goal to decrease development time and cost. These techniques is applied in Paper III where KBE is used to save information necessary to automatically perform different CAE simulations.

Knowledge within a system can be based on two different knowledge constructions: rules and frames. Rules are based on simple if-then constructions, while frames are more complex constructions that use objects and relations among different objects. The frame knowledge representation is tightly coupled to the development of object-oriented programming languages. KBE systems often have a more formal declaration of objects and rules than traditional object-oriented programming languages. A class within a KBE system typically consists of a name, a list of inputs with parameter values specific for the current instantiation of the class, a list of objects that is referred to when an object is instantiated, and a list of functions describing what can be done with the class [47]. 
Table 3: Groups of features within the resilient modelling strategy, adapted from [13].

\begin{tabular}{|c|c|c|c|}
\hline Group & Description & $\begin{array}{l}\text { Typical } \\
\text { features }\end{array}$ & Notes \\
\hline $1-\operatorname{Ref}$ & $\begin{array}{l}\text { All "Reference" entities } \\
\text { are first, making them } \\
\text { available to all features }\end{array}$ & $\begin{array}{c}\text { Ref. Bodies, Images, } \\
\text { Sketches, Ref Planes, } \\
\text { Coord. systems }\end{array}$ & $\begin{array}{l}\text { No } \\
\text { Solids }\end{array}$ \\
\hline 2 - Construction & $\begin{array}{l}\text { Construction features } \\
\text { that will be used to } \\
\text { define complex solid } \\
\text { features }\end{array}$ & $\begin{array}{c}\text { Surfaces, Project, } \\
\text { 3D Curves, Trim, } \\
\text { Split }\end{array}$ & $\begin{array}{l}\text { No } \\
\text { Solids }\end{array}$ \\
\hline 3 - Core & $\begin{array}{l}\text { Core features that } \\
\text { determine the model's } \\
\text { shape, extents and } \\
\text { orientation }\end{array}$ & $\begin{array}{l}\text { Extrude, Sweep, } \\
\text { Revolve, Shell }\end{array}$ & $\begin{array}{c}\text { Add } \\
\text { material }\end{array}$ \\
\hline 4 - Detail & $\begin{array}{l}\text { Detail features } \\
\text { complete the shape } \\
\text { by only linking } \\
\text { to the core group }\end{array}$ & $\begin{array}{c}\text { Extrude, Sweep, Hole, } \\
\text { Revolve, Thread }\end{array}$ & $\begin{array}{l}\text { Remove } \\
\text { material }\end{array}$ \\
\hline 5 - Modify & $\begin{array}{l}\text { Tilt faces and replicate } \\
\text { features, then add } \\
\text { any final features }\end{array}$ & $\begin{array}{l}\text { Draft, Pattern, } \\
\text { Mirror, Final } \\
\text { Features }\end{array}$ & \\
\hline 6-Quarantine & $\begin{array}{l}\text { Volatile features that } \\
\text { should only be } \\
\text { children }\end{array}$ & $\begin{array}{c}\text { Chamfer, Fillet, } \\
\text { Blend }\end{array}$ & $\begin{array}{l}\text { Largest } \\
\text { first }\end{array}$ \\
\hline
\end{tabular}

The combination of knowledge saved in a KBE system and the geometrical modelling approach in high-level parametric CAD modelling enables the automatic creation of designs based on a few, or no, manual inputs [26]. Verhagen et al. [62] state: "one of the hallmarks of the KBE approach is to automate repetitive, non-creative design tasks". Skarka [55] adds that up to 80\% of the time for product development is spent on repetitive tasks, while only $20 \%$ is spent on innovative design tasks. By implementing KBE in the process, the time spent on routine tasks can be minimized, resulting in time for innovative work and a time profit.

In Paper III, KBE was used to save manufacturing information in order to automatically export models for manufacturing and CAE analyses.

\subsection{Design Optimisation}

While parametric CAD modelling and Knowledge Based Engineering are enablers to automatically create and evaluate products, design optimization can be used to find the design that best fits a set of defined requirements. A general optimization problem is formulated with one or more objective functions that describe the goal of the optimization. This can be minimization or 
maximization of cost, performance, weight, or other characteristics. It is also necessary to define what limits the design solution. This is called constraints and can be formulated as inequality or equality constraints. Finally, the type of variables and how they are allowed to change during optimization also have to be defined [45]. An example of a general optimization formulation with two objectives is shown in 3.1.

$$
\begin{array}{ccc}
\min _{x} & f_{1}(x), f_{2}(x) & \\
\text { s.t. } & g_{j}(x) \leqslant 0 & j=1 \ldots m, \\
& h_{j}(x)=0 \quad j=1 \ldots p, \\
& x^{u} \leqslant x_{i} \leqslant x^{l} &
\end{array}
$$

Optimization problems can be classified in several different ways, based on if they are single- or multi-objective problems, if the problem is convex or non-convex, if the objectives and constraints are linear or non-linear, and if the variables are continuous or discrete [45]. The optimization framework for AM, which is proposed in Paper I and implemented in Paper II, includes both functional and manufacturing-related objectives, which makes it multiobjective. Since the objectives and constraints are calculated based on advanced simulation models, the problem is non-linear.

The continuation of the section contains the theory used in the present work, including theory about structural optimization, Multidisciplinary Optimization, and optimization algorithms.

\section{Structural Optimization}

Optimization of geometrical structures can be divided into three types: size, shape, and Topology Optimization (TO), where each type has its advantages and disadvantages. The largest differences between the three are how the design variables controlling the geometry are defined. During size optimization, the geometry is defined as a set of trusses or beams with variables such as thickness and length. In shape optimization, the geometry is based on variables that control a more advanced representation of the geometry. In $\mathrm{TO}$, the geometry is defined as a mesh where the density of each element is used as a design variable. A density of one means that that particular point in the design space should be filled with material, and zero means that it should not [14]. An example of how the results of a simple beam optimization problem can look for the three different structural optimization types is shown in figure 10.

TO is characterized by its free-form possibilities and the possibility of creating a design "out of nothing", compared to the others that typically start from an initial structure. The input for a TO is a geometrical design space (where placing material is allowed) with corresponding material properties, 


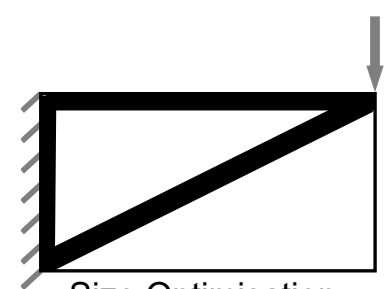

Size Optimisation
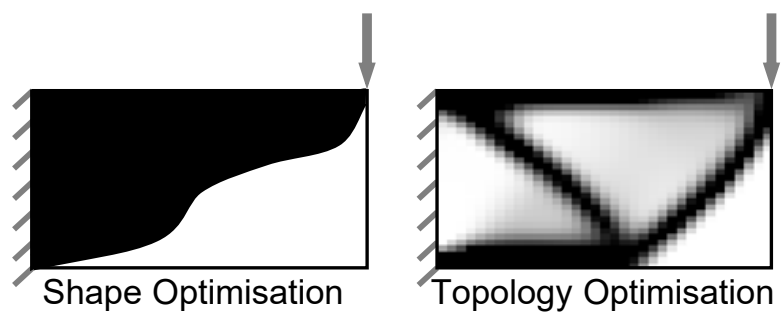

Figure 10: An example of what the result from the three structural optimization types could look like.

a set of load conditions, constraints for the optimization, and an objective function. Before the optimization starts, the defined design space is meshed, and the density of each mesh element is used as a design variable during the optimization. For each design iteration, a FE analysis is performed and based on the result the design variables are updated before the next iteration. The constraints and objective functions of the optimization can be formulated in different ways, but two of the most common ways are: minimization of compliance (deformation of the structure) while a certain percentage of the design volume is filled with material; and minimization of mass while the stress level is constrained. The output from TO is the optimal distribution of material based on the optimization setup realized in the form of a geometric mesh. Central to TO is the FE analysis, and even though a lot of effort has been put into the creation of formulations that take into account manufacturing features, thermal analysis, and others, TO is primarily a tool for the creation of structures based on structural requirements, such as stiffness under mass or stress constraints.

In this thesis, the connection between TO and shape optimization form the base for the automated DfAM process presented in Paper I. Since shape optimization requires a parametric CAD model with design variables coupled to geometrical features, an automated DfAM process requires a coupling between TO results and parametric CAD. In Paper II, this is a manual process, and Paper III presents a method to overcome this gap.

\section{Multidisciplinary Design Optimization}

The usage of parametric CAD models in shape optimization creates the potential to include one or several other CAE software into a common optimization framework. Since real-world design problems are often more difficult than a structural evaluation with solely one objective, shape optimization can gradually evolve into more advanced formulations [6]. In Multidisciplinary Design Optimization (MDO), multiple CAE tools are combined in order to analyze a design from several perspectives, and the result is that a 
variety of characteristics can be used as constraints and objectives. This often includes characteristics from both the design and business perspectives [56].

\section{Optimisation Algorithms}

There are a multitude of methods and algorithms to solve different optimization problems. These can be divided into two categories: derivative and nonderivative methods [6]. As the name implies, the derivative methods use different degrees of the derivative of the objective functions in order to find the optimum, while the non-derivative methods are often considered as blackbox methods. The derivative approaches typically conduct the search in the direction for where the derivative of the objective functions is the greatest. This make the methods effective for simple convex problems without several local optima. On the other hand, the non-derivative methods do not get stuck in local optima but search for global optima. However, they often require more design evaluations.

Genetic Algorithms (GA) is a non-derivative type of evolutionary optimization algorithms that mimic evolution in nature to find an optimum design [20]. The method is built around several generations of design solutions, each generation of which contains a set of individuals. For each generation, the individuals with the best objective values are mated with each other in order to create new individuals for the next generation. The individuals are represented by a chromosome that is created based on the design variable values. During the mating, the chromosomes of the different individuals are combined with each other so that the offspring receive some information from each of the two parents. GAs are robust and work for a large set of different problems, and they are also easily adopted for multi-objective optimization, see for example [16]. The downside of GAs is the optimization time, as a large number of design evaluations are necessary to reach convergence

Paper II compares derivative and non-derivative optimization approaches to optimize the build direction of a part. While the derivative method finds the best build direction to minimize the need of a support structure needed during AM, the non-derivative method ends up with a local minimum. A multi-objective GA is also used to optimize the shape of a geometry in order to minimize both the amount of support structure and the weight of the part. 


\section{Computer Support for DfAM}

The three appended papers are summarized in this chapter. The papers explore the type of computer support that is favorable when designing for AM, how AM computer support should be used, and how the support can be designed. The chapter is divided based on the three appended papers where the method used, the contribution, and the conclusions for each paper are presented.

\subsection{Paper I - A review of DfAM methodology}

Paper I consists of both an elaborated review of research published in the area of design for AM and a proposal for a future DfAM process. The review includes terminology, trends, classification, generic and specific design methods, and existing software. The identified literature was compiled to a state-of-the-art design process with support in the form of specific methods or software mapped to each step in the design process. This review is the foundation for the theory presented in section 2.2, and is described in detail in Paper I. The proposed future design process is presented in this section.

\section{Applied Method}

The method used during the review consisted of six rounds of search, categorization, and selection of publications. In the first round, publications were identified by implementing different search words and strings in a search engine. Rounds two to four were dedicated to the systematic review and removal of the publications identified in the first round. Snowballing was used in round five to identify publications not previously identified. Round six was dedicated to the identification of software supporting the DfAM process. Over 6000 publications were identified and reviewed during the process. An overview of the activities during the review process and the number of publications revised during each step is presented in figure 11 . 


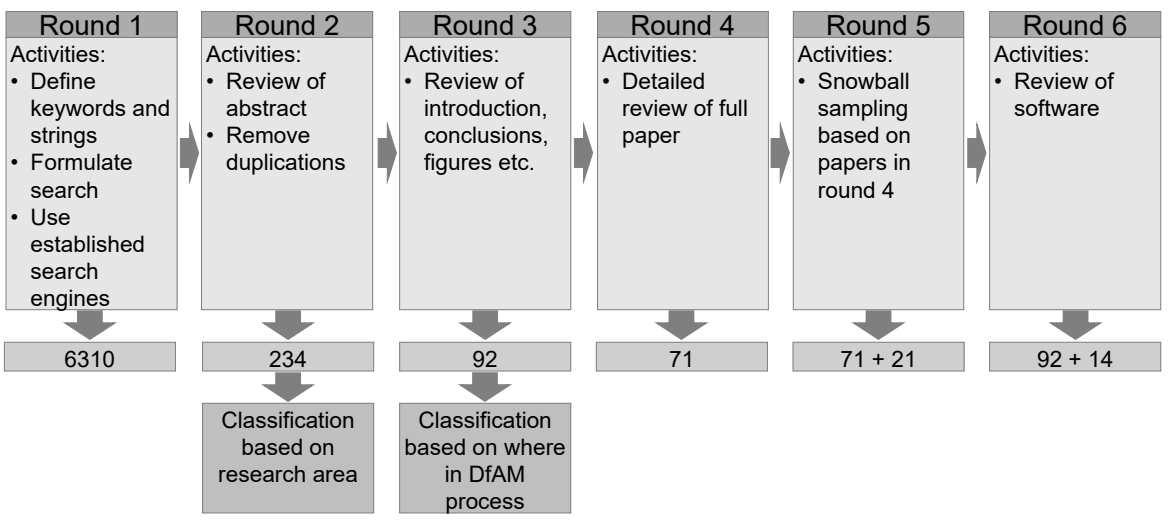

Figure 11: Method used during the review process.

\section{Results and Contribution}

The review showed that today's design process and software mainly focus on an iterative process where steps need to be repeated manually based on information gained in later steps. An alternative process based on a design automation approach is proposed in order to achieve a design process with less repetitive work. If the repetitive work of editing the design based on manufacturing, structural, and other performance information can be reduced, time can, instead, be spent on creative tasks. This has the potential to lead to better and cheaper components.

The proposed design automation process includes the same design steps as the best practice design process (presented in figure 7) but with an automatic feedback loop between several of the steps. As shown in figure 12, the first three design steps, where a component suitable for AM is chosen and the design problem is defined, still need to be performed manually.

The following design steps, including the creation of the initial design, interpretation of the initial design, and evaluation of manufacturing and functional demands are incorporated into a design automation framework. This creates an integrated design process where component function and manufacturing are optimized simultaneously. Central to the framework is a parametric CAD model that is based on the initial design. This model should be able to represent the shape of the result from the initial design but also be sufficiently flexible to transform varied shapes based on functional and manufacturing feedback. In addition to being flexible, the interpreted parametric model should also be able to export models adopted for various functional and manufacturing simulations in the design automation loop. 


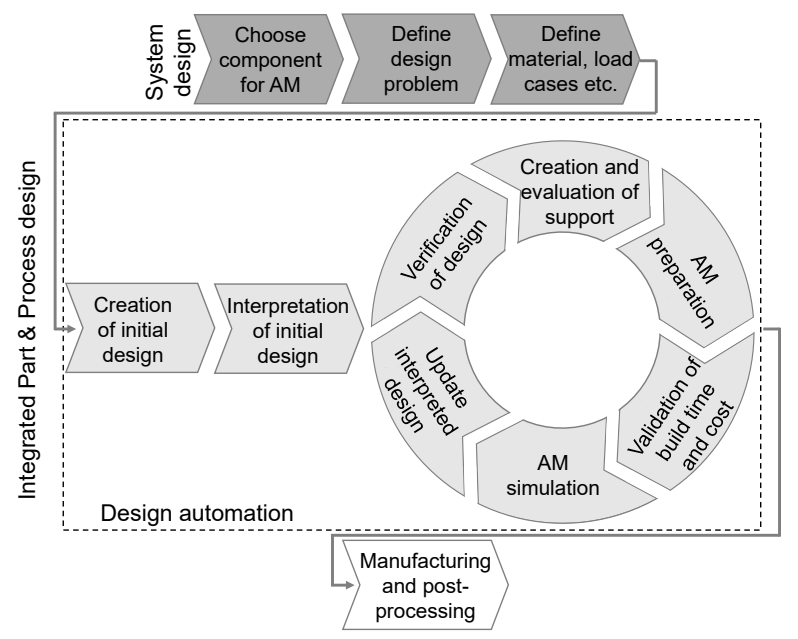

Figure 12: Simulation driven design process for AM, as an enhancement of the state-of-the-art process presented in figure 7.

\section{Conclusions Paper I}

Paper I presents an extensive review of the field DfAM, where the focus is on the role of the design engineer in the DfAM process. A state of the art DfAM process is presented and existing publications are coupled to each step of the process. A summary of these findings is presented in section 2.2. A contribution to existing research is made in the form of a presentation of an improved DfAM process that is based on design automation. The design automation process includes the same steps as the state-of-the-art process but with an automatic feedback loop between several of the steps is used to achieve design automation.

Further details of the performed review and the proposed process can be found in Paper I. Part of the proposed process is implemented in a computer tool and applied in Papers II and III.

\subsection{Paper II - A DfAM case study}

Paper II consists of a case study that demonstrates selected parts of the design process presented in Paper I. The case study focuses on essential parts of the proposed design automation DfAM framework, where a parametric CAD model is used to optimize both the functionality and the manufacturability of a specific component. In this study, an upright in a formula student car [37] is designed using the proposed optimization framework. While the design process in Paper I proposes advanced manufacturing simulation in 
the design automation framework, a simpler geometrical-based evaluation is used in the case study.

\section{Applied Method}

The method applied in Paper II is based on the automated design for the AM process shown in figure 12. However, the method is limited to one model for structural verification and one model for support structure evaluation. The work of interpreting the initial design into a parametric CAD model is also done manually.

In the paper, Topology Optimization is used for the creation of an initial design. A parametric CAD model is created and used for functional evaluation of a component including weight calculations, and it is also used for verification, so that the stresses do not exceed the material's yield limit. One model for the evaluation of the manufacturability is implemented, which evaluates how much support material is necessary during the build process. The method is shown in figure 13.

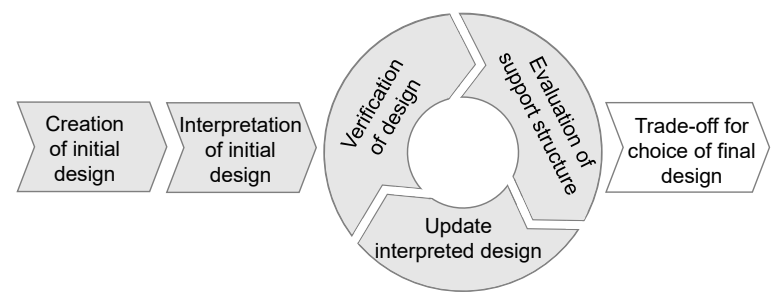

Figure 13: Method used in Paper II.

\section{Results and Contribution}

In the case study, the interface to other components and a worst-load-case were given by the formula student team. Based on the given interfaces, a design space was created. The design space was, together with the given load case, used for the performance of a TO of the component. The TO was performed with the objective of minimizing weight and with the maximum allowed stress as a constraint.

The result from the TO was used to inspire the creation of a parametric CAD model. This was done manually but with a structured method where trusses were created by combining splines with cross-sections along each truss. Both the splines and the cross-sections were able to be changed based on parametric input variables. An example of the creation of the parametric CAD model is shown in figure 14 .

The parametric CAD model was used to evaluate the mass of the structure, and it was also used in an FE model to calculate the stress in the struc- 

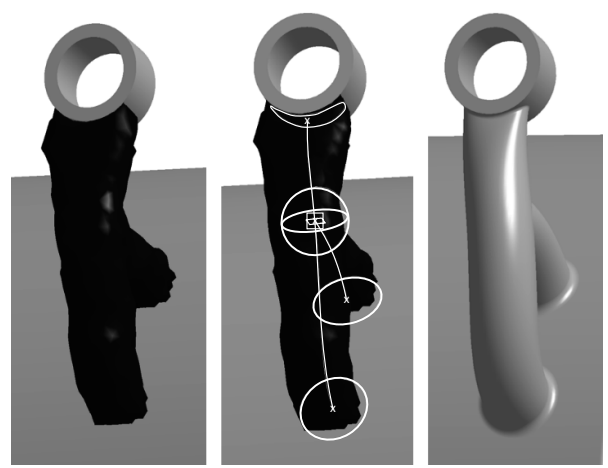

Figure 14: Example of the method used for creation of the parametric CAD model.

ture. Finally, a model that calculates how large an area of the model that is in need of support structure during the build process was created. These models were combined in two different optimization frameworks, both of which aimed to minimize the mass of the component and the amount of support structure needed, while ensuring that the stress constraint was not violated.

The two frameworks differed in the way they were formulated to solve the problem. Framework I was distributed where one global and one local optimization were used to solve the problem. In the global framework, parameters coupled to the geometry were varied. In the local optimization, the build direction was changed during the optimization. In Framework II, a monolithic optimization formulation was used where both the geometry and the build direction were considered at the same time. An illustration of Framework I is shown in figure 15, and Framework II is illustrated in figure 16.
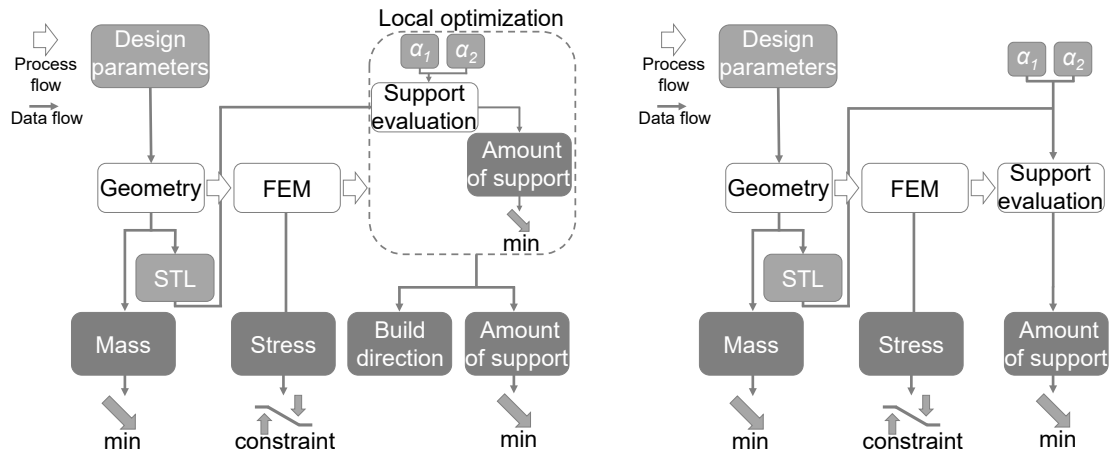

Figure 15: A distributed multidisci- Figure 16: A monolithic multidisciplinary optimisation framework for plinary optimisation framework for AM. AM. 
Equation 4.1 shows the mathematical formulation of the global optimization in Framework I. The formulation for the local optimization is shown in 4.2.

$$
\begin{array}{cc}
\min _{\mathbf{x}} & F(\mathbf{x})=\left[f_{1}(\mathbf{x}), f_{2}(\mathbf{x})\right] \\
\text { s.t. } & g(\mathbf{x})<\sigma_{\max }, \\
& \mathbf{x}=\left[x_{1}, x_{2}, \ldots, x_{n}\right], \\
& x_{i, \min } \leqslant x_{i} \leqslant x_{i, \max } \\
\min _{\alpha_{1}, \alpha_{2}} & f_{2}\left(\alpha_{1}, \alpha_{2}\right) \\
\text { s.t. } & 0 \leqslant \alpha_{1} \leqslant 180, \\
& 0 \leqslant \alpha_{2}<360
\end{array}
$$

The mathematical formulation for optimization Framework II is shown in equation 4.3.

$$
\begin{array}{cc}
\min _{\mathbf{x}, \alpha_{1}, \alpha_{2}} & F\left(\mathbf{x}, \alpha_{1}, \alpha_{2}\right)=\left[f_{1}(\mathbf{x}), f_{2}\left(\mathbf{x}, \alpha_{1}, \alpha_{2}\right)\right] \\
\text { s.t. } & g(\mathbf{x})<\sigma_{\max } \\
& \mathbf{x}=\left[x_{1}, x_{2}, \ldots, x_{n}\right] \\
& x_{i, \min } \leqslant x_{i} \leqslant x_{i, \max } \\
& 0 \leqslant \alpha_{1} \leqslant 180 \\
& 0 \leqslant \alpha_{2}<360
\end{array}
$$

In all formulations, $x$ represents variables that manipulate the geometry of the component, whereas the alfas represent the build direction. A genetic optimization algorithm was used for the global optimization in Framework I and the monolithic optimization approach in Framework II. A comparison between different optimization algorithms was performed for the local optimization in Framework I. Different settings for genetic algorithms and gradient-based algorithms were evaluated. It was concluded that the starting point of the gradient-based algorithms highly influenced the result as the optimization often got stuck in local optimums. Therefore, a genetic algorithm was chosen for the local optimization.

On a desktop computer (Intel Core I7-62820HQ CPU 2.70GHz, 8GB RAM), the simulation time per design for Framework I, including local optimization, is around 5 minutes and 30 seconds. An optimization with 60 individuals and 30 generations resulted in a total optimization time of $142 \mathrm{~h}$ and 30 minutes. The simulation time per design for Framework II is around 1 minute. 70 individuals and 40 generations were used for the optimization, and this resulted in a total optimization time of 46 hours and 40 minutes.

Some of the designs from the Pareto fronts achieved from the distributed approach in Framework I and the monolithic approach in Framework II are 
presented in figure 17. Design 1-3 in the figure originates from Framework I, while Design 4-7 originates from Framework II. An analysis of the result direct from the TO is shown in the figure.

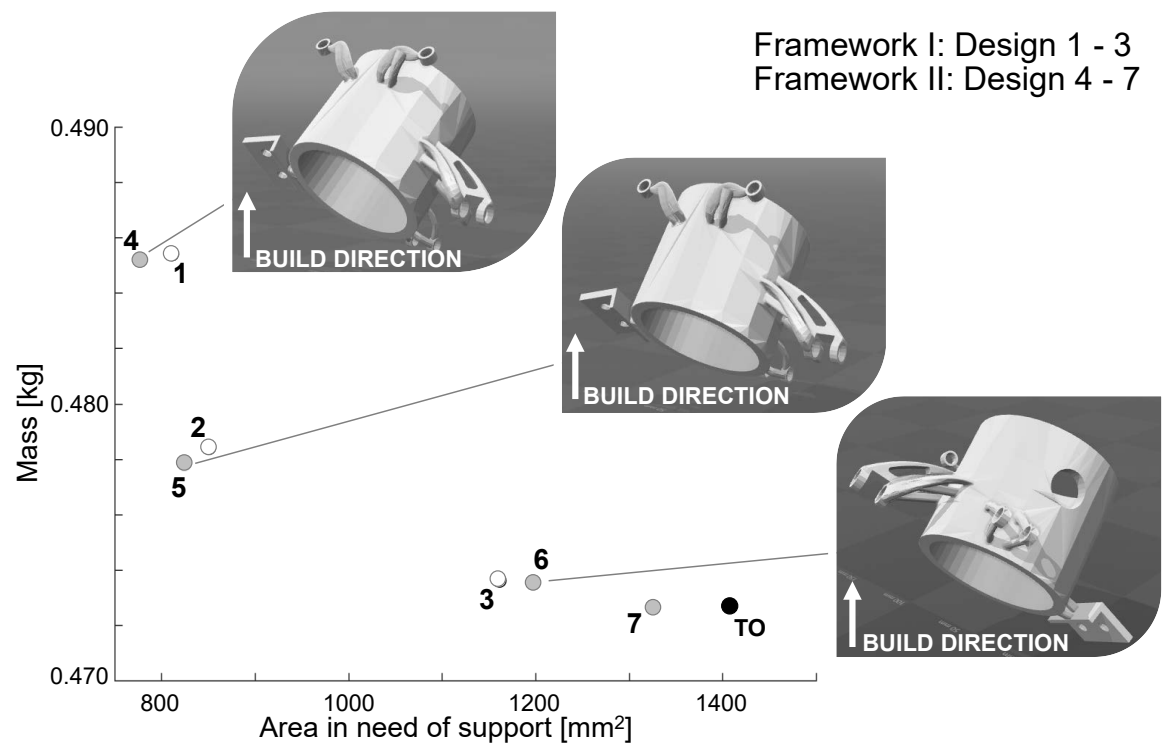

Figure 17: Results from the performed optimisation.

When the results from Framework I were studied separately, it was concluded that the results had not converged. This explains why Framework I shows worse results for Designs 1 and 2 than for Designs 4 and 5 from Framework II. The results from Framework II are, thus, comparable to or better than the results from Framework I and were also achieved one third of the time.

The results show that the proposed optimization framework could achieve designs with a weight similar to the result directly from the TO but with six percent less support. The same framework also came up with a design with a weight increase of three percent but with 45 percent less support material. A more detailed discussion of the proposed method and the obtained results are available in Paper II

\section{Conclusions Paper II}

Paper II presents a study where an upright of a formula student car was designed using a design automation framework. The design framework contained the essential step of the DfAM process proposed in Paper I. Topology Optimization was used in the paper for the creation of an initial design. The TO was manually interpreted into a parametric CAD model. The parametric 
CAD model was used in a design automation framework that automatically verifies functional and manufacturing characteristics. Functional verification was done in the form of structural and weight analyses. Manufacturability was analyzed with a model that evaluates the amount of support structure needed during manufacturing.

The work indicates great potential to increase the manufacturability of a component if the objectives coupled to functionality and manufacturing are combined as proposed in Paper I.

\subsection{Paper III - Development of a tool supporting the DfAM process}

Paper III focuses on the development of a method for how geometrical information can be handled during an automated design for the AM process. The study presents a method that supports the transformation of results from an initial design created with $\mathrm{TO}$ to an interpretation of the initial design. The interpreted design is in the form of a parametric CAD model. In addition to easy change of the model, the presented method also allows automatic export of models for functional and manufacturing verification. The method was implemented in a tool that uses KBE to create the parametric CAD model. The tool also enabled the storage of manufacturing information that could be used to export models for manufacturing along with a model for structural analysis. The tool was applied on a structural component that was part of an aircraft door.

\section{Applied Method}

The aim of Paper III was to overcome the gap between the initial design and the interpreted design, see figure 12. The method in Paper III takes a closer look at the particular part of the DfAM process proposed in Paper I. The interpreted geometry is central to this process and has to be easy to change, flexible, and able to prepare geometries for manufacturing and CAE verification. The model should also be possible to create with as little manual input as possible.

Paper III proposes using a master model approach to save information during the design process. The master model contains information that makes it possible to automatically adjust the geometry and make changes in order to export models for different usage. For manufacturing, a model needs to contain information that supports the generic AM process presented by Gibson et al. [19]. This includes the steps CAD, STL, AM prepared geometry, machine setup, build, removal, post-processing, and application. Figure 18 shows a proposal for how information coupled to the geometry can be handled during the design process. A file for manufacturing is created based 
on the master model, while the interpreted geometry (or master model) represents what the final geometry should look like. The manufacturing geometry represents what the geometry should look like after manufacturing, but before additional post processing. Compared to the interpreted geometry, this could have additional material on surfaces that need to be postprocessed, for example, with traditional milling. The manufacturing geometry is prepared for manufacturing by being sliced and path planned. The geometry after the AM manufacturing, referred to as Manufactured geometry, contains support and other additional material that is removed before the final geometry is achieved. In this process, the manufacturing geometry can be used for CAE validation of design rules, while the AM prepared geometry forms the base for simulation of the AM process.

In parallel to the validation of manufacturing, the geometry is also validated for functional requirements through various CAE analyses. The CAE analyses aim to represent the behavior of the component for a specific analysis, and the geometry therefore needs to be adapted for each specific analysis. Only structural validation is implemented in the tool developed in Paper III, but the method is general and can be applied to other CAE analyses.

Figure 18 shows the method where a Master Model, interpreted from a TO result, is the base for preparing geometries and information for manufacturing along with functional verification.

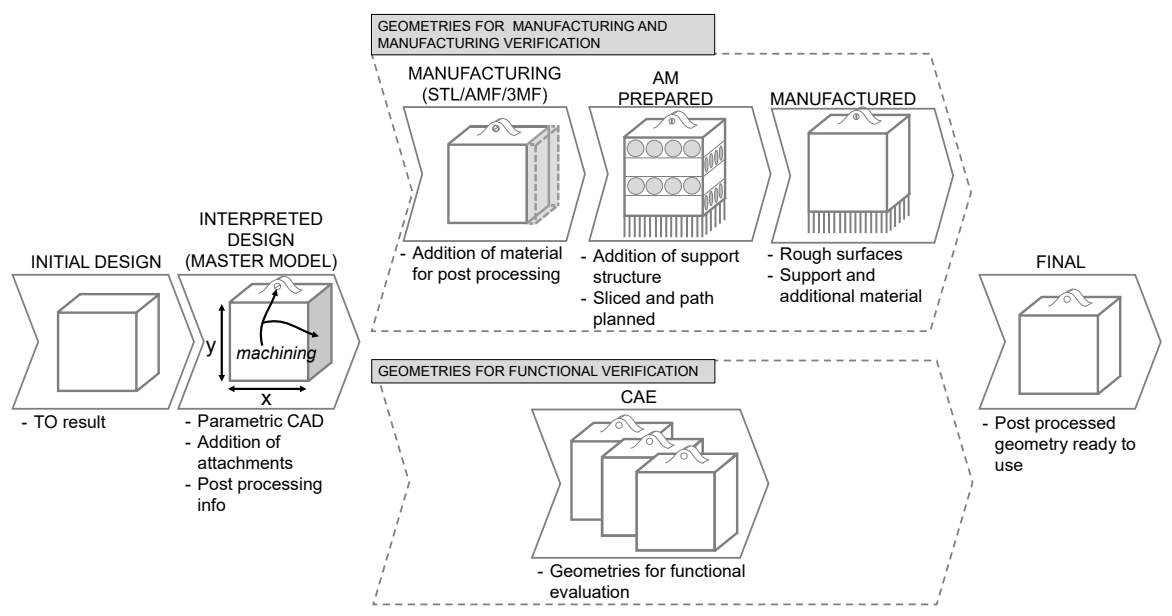

Figure 18: A Master Model approach to support an automated DfAM process.

\section{Results and Contribution}

The methodology applied in Paper III was realized with CAD templates that were instantiated into a CAD system. The CAD templates were formalized in 
an object-oriented programming language where each knowledge template corresponds to a programming class. The classes consist of three types of attributes: Reference; Relation; and Information. The Reference attributes correspond to parameters that control the topological instantiation of the CAD template in the CAD system. These attributes also create a connection between the different objects in the system. The Relation attributes control parameters coupled to morphological changes. Information attributes contain information that affects the geometry during the export of manufacturing or CAE models. Each programming class contains three methods that can create, modify, and delete an object. In addition to these three methods, the class can also contain methods that apply changes to the geometry when models for manufacturing and CAE are exported. These changes are controlled by the Information attributes. An example of a class is shown in figure 19.

\begin{tabular}{|c|c|c|c|}
\hline Instance 1 & Instance 2 & & \\
\hline Ball1 & Ball2 & Name & Identity \\
\hline position = pos 1 & position = pos2 & Reference & \\
\hline size $=15.3$ & size $=12.5$ & Relation & Attributes \\
\hline colour = "Red" & colour = "Blue" & Information & \\
\hline create() & create() & & \\
\hline modify() & modify() & & \\
\hline delete() & delete() & & Methods \\
\hline exportManufacturing ( & exportManufacturing & & \\
\hline exportCAE1() & exportCAE1() & & \\
\hline
\end{tabular}

Figure 19: Format of the objects used to save different kind of information.

In parallel to the CAD model, it is proposed that information is saved in a relational database coupled to the system. The relational database has four tables (A-D) where Table A consists of the ID number and the name of the instantiated object, Table B consists of the ID number and the type of class, Table $\mathrm{C}$ consists of a list of the attributes that exist for each class, Table D contains the values of the attributes for the instantiated objects. An example of what the database would look like for the objects in figure 19 is shown in table 4 .

The proposed method uses a function-mean modelling approach to identify the classes when a system is developed. This is showcased by the development of a system for the creation of parametric CAD models of structural components based on TO results. The main functions of a structural component are to transfer loads among components and to attach to other components. Two means (rivet and bolt) are implemented to attach to other components. For the transfer of loads, the creation of a truss structure is supported, as described in Paper III. 
Table 4: Example of the relational database used.

\begin{tabular}{|c|c|c|c|c|l|l|l|l|}
\hline \multicolumn{2}{|c|}{ Table A } & \multicolumn{2}{c|}{ Table B } & \multicolumn{2}{c|}{ Table C } & \multicolumn{2}{|c|}{ Table D } \\
\hline ID & Name & ID & Class & Class & Attribute & ID & Attribute & Value \\
\hline 1 & Ball1 & 1 & Ball & Ball & Position & 1 & Position & Pos1 \\
\hline 2 & Ball2 & 2 & Ball & Ball & Size & 1 & Size & 15.3 \\
\hline & & & & Ball & Colour & 1 & Colour & Red \\
\hline & & & & & & 2 & Position & Pos2 \\
\hline & & & & & & 2 & Size & 12.5 \\
\hline & & & & & & 2 & Colour & Blue \\
\hline
\end{tabular}

The developed system is supported with a user interface that is divided into four different sections. As seen in figure 20, the model is prepared in the first section, and the surrounding components and $\mathrm{TO}$ result are imported into a common assembly. The means that solve the identified functions are created in the second and third sections. During this process, the interface guides the user by sometimes describing actions that need to be done in the CAD system and sometimes asking the user for references or information regarding manufacturing. The fourth section of the developed interface contains functions for the export of a model for manufacturing and manufacturing simulations, and another function for FE analysis. These functions call the method of each instance in the system and implement adjustments of the geometry based on Information attributes. The interface of the developed system is shown in figure 20.

The developed tool is evaluated in Paper III by implementing it in the demonstrator developed during the AddMan project. The demonstrator consists of a lift fitting that transfers forces between an airplane door and an actuator. As seen in figure 21, the TO result is rebuilt with different features for connections between the door and the actuator, and with a truss structure connecting the different attachments. Further details on the method and the application are presented in Paper III.

\section{Conclusions Paper III}

Paper III presents a method that supports the design-automation-based DfAM process proposed in Paper I. The method bridges the initial design step, the interpreted design step, and the integrated part and process design. The proposed method is implemented in a tool that supports the creation of a parametric model based on TO results. By using a master model approach, information regarding manufacturing and simulation can be saved and can utilize the automatic export of models for different purposes. This enables faster design changes that, in a subsequent step, can be used to enable MDO for AM. 


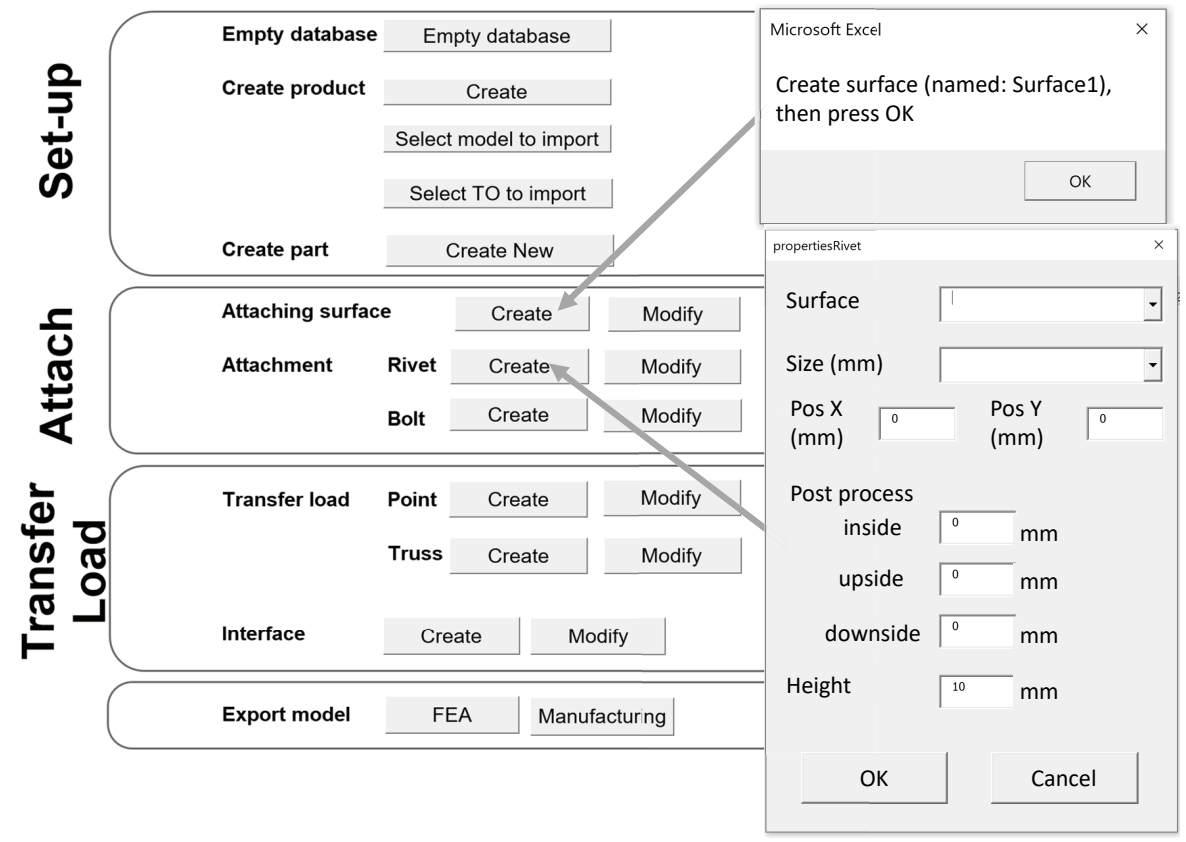

Figure 20: Interface of the tool developed for creation of CAD models based on $\mathrm{TO}$ results.

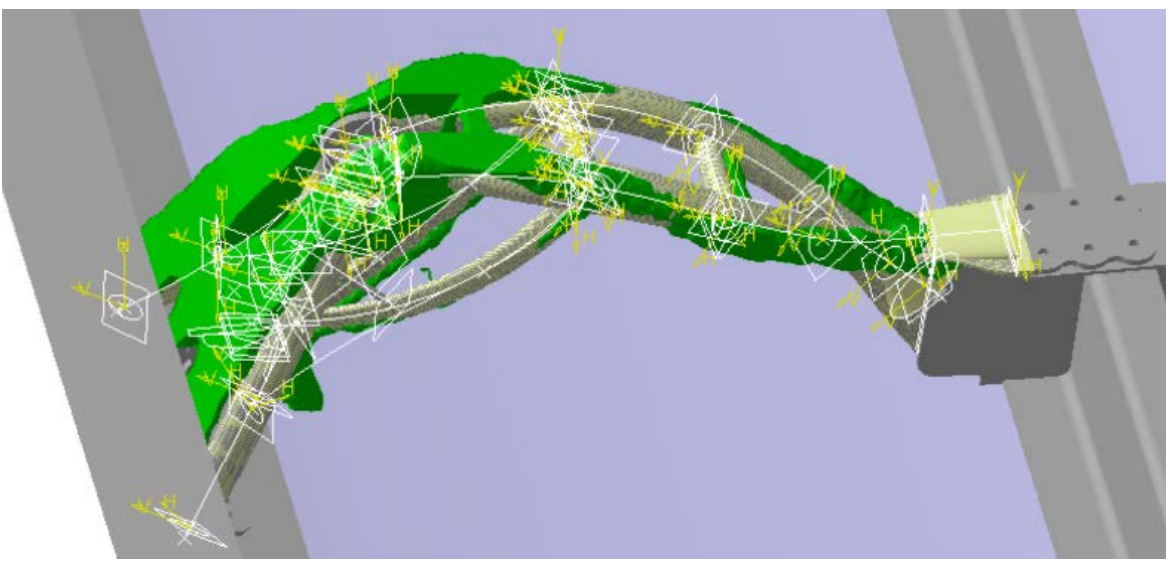

Figure 21: Example of geometry created by the tool developed in Paper III. 


\section{Discussion}

The presented work is discussed in this chapter from different perspectives. First, the overall research method used during the work is discussed, followed by a discussion of the presented work. The chapter is rounded off with a discussion of the work in a larger context. This includes a discussion regarding implementation in industry and a discussion of this research in contrast to the technical development performed by commercial companies.

\subsection{Research Method Discussion}

The Design Research Methodology (DRM) applied during the work has been found to be effective in various design research applications previously. The author, therefore, judged that it was an appropriate choice of method for the present research. However the method has not been followed all the way since the study in Paper III did not cover the whole design method proposed in Paper I. The descriptive Study II in the DRM should also comprehend a larger scope with several studies to evaluate the work [11]. As the name of the thesis, "Towards Design Automation for Additive Manufacturing", implies the work is to be seen as a step in the direction of design automation for $\mathrm{AM}$ and not a finalized scope. The deductive approach with smaller studies aims to give enough data to verify the research. More studies that evaluate the proposed methods and tools are necessary to truly support the findings herein.

\subsection{Results Discussion}

The discussion of the results of the work is divided into the same three levels as the scope of the thesis (see section 1.2), namely: DfAM Methodology, Tools, and Applications. 


\section{DfAM Methodology}

Methodologies for DfAM were, to different extent, addressed in all three appended papers. A methodology based on existing research is presented in Paper I and is followed up with a proposal for how several disciplines could be connected to achieve design automation. Paper II shows how the methodology proposed in Paper I can be employed to automate parts of the design process. Paper III focuses on the geometrical representation and model handling within an automated DfAM process. Within the work in Paper III, a method and tool that demonstrate automatic model handling in the process are shown.

One of the most mentioned techniques for DfAM in current literature is Topology Optimization (TO). TO is attractive since it can create complex shapes without difficult and time-consuming CAD modelling. TO also satisfies one of the three advantages (creation of lightweight designs) of AM presented by Klahn et al. [34]. However, most authors agree that direct usage of TO results are not possible. The development of new TO algorithms and filters is, however, quickly developing, and it may be possible to use $\mathrm{TO}$ results directly for manufacturing in the future. An approach where TO is used as inspiration for a parametric CAD model used in an MDO framework is proposed, instead, in the present research. This approach adds a difficult step of interpretation of the TO result into a parametric CAD model. The advantages of this approach are, however, greater as MDO is a flexible method where different $\mathrm{CAE}$ analyses can be conducted during the design process, which is not possible in a pure TO implementation. Another advantage is the potential to use several objectives that can be added, removed, or modified, depending on the purpose of the component.

While TO is suitable for finding the optimal distribution of material to make a structure lightweight, the other two advantages of AM presented by Klahn et al. [34], the creation of individual designs and the creation of complex geometries with integrated functionality, are more difficult to fulfill. Function-mean modelling is used in the CAD method presented in Paper III in order to identify how features in the geometry are connected to the function of the component. In future work, this can be taken a step further and a similar approach can be used to create integrated functionality in the geometry. This would create the potential to include the optimization of the integrated functionality within the design automation framework.

\section{DfAM Tools}

There are several different software that can be used for DfAM, most of which have been separately developed based on research in different areas, such as TO, CAD, CAE, and manufacturing simulation. Software developers have recently started to integrate these tools into common packages and 
have tried to make them work better together for an integrated workflow. However, this software development is not driven from a product development perspective with the efficiency of the AM designer in mind. There is research that focuses on product development coupled to the DfAM process, but it has not yet been realized in the form of software or tools. One aim with the present research is to identify where the largest gaps in the tools are, and to propose directions for the development of new ones.

An MDO approach to product design has major challenges when it comes to software development and integration. One of the biggest challenges with detailed design using MDO is the geometry handling where the geometry needs to be flexible, robust, include all details, and be able to provide the correct information to automate several different CAE simulations. Paper III deals with the development of a tool that aims to reduce the gap between the rigid TO design and the flexibility of a parametric CAD model. The method creates a guide for how the user should design the CAD model and reduce the manual work needed. One of the largest challenges of the tool is the ability to create detailed features automatically. Parallel to the development of the tool, collaboration partners have used commercial software for the creation of the same geometry as the tool developed in Paper III. This research has found that the creation of detailed features is difficult with commercial software.

A design automation framework with the essential parts of the design process proposed in Paper I is realized in Paper II with commercial software. The solutions for geometrical representation, structural analysis, and manufacturing analyses are integrated in commercial software for MDO. This framework can be reused for other design tasks if the CAD model and structural model are updated.

\section{DfAM Applications}

The DfAM applications in the thesis have been used in an attempt to verify the proposed method and developed tools. The application in Paper II is (as proposed in the Design Research Method [11]) used to create understanding and provide evidence that the proposed process is valid. In a similar way, the component application in Paper III provides evidence that the developed tool has the potential to create relevant models.

Since the focus of the AddMan project is on structural components, both of the components studied in the two applications were structural where forces are to be transmitted among different attachment points. Together these two components verify that the proposed DfAM process works for these types of components.

In contrast to Topology Optimization, the application in Paper II shows that the proposed DfAM process can handle multi-objective optimization problems with objectives coupled to both function and manufacturability. 
To connect to the three reasons for using the AM presented by Klahn et al. [34] (individualized designs, complex structures with integrated functionality, and lightweight designs), the application in Paper II shows that the proposed design process is capable of creating lightweight designs. Since the parametric CAD modelling approach used in both applications enables easy changes to the product, the proposed design process also has the capability to create individual designs without any extra remodeling. However, how the proposed DfAM process can be used to create structures with integrated functionality is not covered in the two applications.

\subsection{The work in a wider context}

The topic DfAM is popular, and people from industry, research, and software developers are working within the area at the moment. This means there is a fine line between technical development, research, and software development. When it comes to manufacturing companies and software developers, the industry has huge resources and employees with vast experience in the development of user-friendly and effective solutions.

The work performed within this thesis focused on DfAM on different levels, everything from DfAM in a general product development methodology to how details of features in CAD software can be used to automate the design process. Applications of the methods were also performed to verify and show the applicability of the methods. This broad view of DfAM has created an understanding of problems and opportunities in the DfAM area. However, it is not feasible, within the scope of a PhD project, to develop software that supports the full scope of the proposed methods, such as commercial software. Instead, the hope is that the presented findings can inspire and influence researchers and people from industry to develop methods and software that support the proposed design process. 


\section{CHAPTER}

\section{Conclusion}

The presented work is wrapped up and concluded by answering the research questions stated in section 1.2. Since the research questions are formulated in a broad way, the answers are of a reasoning character rather than a direct answer. The chapter ends with an outlook for future possibilities and by pointing out possible directions for further research.

\subsection{Answering the Research Questions}

RQ1: What is the state of the art when it comes to DfAM?

Current research in the field of DfAM is reviewed in Paper I, and based on the identified publications, a state-of-the-art DfAM approach is proposed. The state-of-the-art DfAM approach consists of three design levels: System design; Part design; and Process design. The System design level contains different activities that choose components for AM, define the boundary conditions, and identify if several components can be merged into one. Part design is where a single component is designed for AM, which includes steps such as Topology Optimization and verification of design using various CAE simulations. The final design level, Process design, verifies the created geometry from a manufacturing perspective. This includes the checking of AM design rules, the creation of support structure, and AM simulation. This process is highly iterative where manufacturing rules and the verification of functional requirements are nested with the design process. Feedback on the support material created and simulation of the manufacturing can also influence the design and shape of a product. The compiled DfAM process is briefly presented in section 2.2 and in detail in paper I.

RQ2: How can a higher degree of design automation in the DfAM process be achieved? 
A higher degree of design automation in the DfAM process can be achieved by using a Multidisciplinary Design Optimization approach where several disciplines for functional and manufacturing evaluation are coupled together. Paper I presents the disciplines that need to be connected in order to achieve design automation. The feasibility of such a framework is demonstrated with a case study implementation in Paper II. With a combination of a model for structural analysis and manufacturing evaluation, both functionality and manufacturability can automatically be evaluated and optimized.

Central to the automation of the design process are geometrical models that are easy to create, change, and use for various CAE simulations. In Paper III, a framework for the creation of such models is proposed and implemented in a tool. Parametric CAD templates are used to simplify the creation of the CAD models. At the same time as the CAD model is created, information regarding manufacturing is saved and stored. The saved information utilizes the automatic export of models for manufacturing and functional evaluation.

\section{RQ3: How could design tools that support a future DfAM process be structured?}

In order to achieve a better design process for $\mathrm{AM}$ with less manual redesign work, it is suggested aiming for a design tool with a tighter coupling between geometry, manufacturing, and functional evaluation. Paper III presents how a tool that supports the creation of a flexible parametric CAD model can be structured. A design tool for AM should bridge the creation of geometries with TO with the ability to optimize the geometry with respect to manufacturing and function. The tool should also make it possible to easily investigate how different parameters (such as the choice of material, AM technique, AM machine, and manufacturing setup) affect the manufacturing. This includes design requirements (such as design rules), cost of manufacturing, and the functional performance of the designed component. In the ideal case, a tool should make it possible to easily investigate the effect of the mentioned changes and also to automatically choose the best design and manufacturing setup based on given inputs.

\subsection{Outlook}

The presented work addresses what a future DfAM process can look like and how this process can apply and implement a subset of the process on test cases. The presented work shows a tool which aids the design process. To fully realize the proposed design process, additional work is necessary in several different areas. Future work can be divided into two separate issues: one part would be to make the tool developed in this thesis easily accessible for a broader audience; and another would be to extend the developed tools 
to cover a larger part of the proposed design-automation-based DfAM process. Future research could also include the validation and verification of the proposed process based on quantitative and qualitative studies in industry and in the DfAM community.

The tool developed in Paper III needs several improvements in order to be distributed for public use. The biggest improvements necessary are error handling and the creation of connections between the structure and the attachment features. To verify the usability of the tool, a study where several different persons use the tool in different industrial settings would be necessary.

To realize design automation in the DfAM process, several issues still need to be addressed. These include issues that are partly addressed within this thesis and issues that are not. Generally, a tighter connection between the geometry, different types of evaluation of component behavior and optimization needs to be developed. This requires further development of the methodology software support, which currently does not exist.

Concretely, it is proposed that future research should focus on the following:

- Evaluate the validity of the proposed process and tools through the application of more test cases, and also encourage experts in the DfAM area to use and evaluate the proposed tools and methods.

- Further development of the integration between TO and parametric CAD models suitable for integration in a design automation framework.

- Investigate how the design of products with integrated functions can be combined with design automation.

- Development of a methodology for how the evaluation of AM manufacturing, including manufacturing cost, constraints, build stresses, deformations, surface roughness, material behavior, and post-processing, can be automated.

- Conduct full MDO studies on real industrial cases based on the proposed methods and tools. 



\section{Bibliography}

[1] 3Dsim. Additive Manufacturing Simulation. URL: http://3ds im.com/ (visited on 06/28/2017).

[2] 3MF Consortium. Specification - 3MF. 2018. URL: https : / / 3mf . io/ specification/ (visited on 11/19/2018).

[3] Kristian Amadori, Mehdi Tarkian, Johan Ölvander, and Petter Krus. "Flexible and robust CAD models for design automation". In: Advanced Engineering Informatics 26.2 (2012), pp. 180-195. ISSN: 14740346. DOI: $10.1016 / j$.aei.2012.01.004.

[4] Hanne Andersen and Brian Hepburn. Scientific Method. 2016. URL: https : / / plato. stanford. edu / entries / scientificmethod/\%7B\%5C\# 7DPopFal.

[5] David M. Anderson. Design for manufacturability : How to Use Concurrent Engineering to Rapidly Develop Low-Cost, High-Quality Products for Lean Production. Boca Raton, Fl: Taylor \& Francis, 2014. ISBN: 9781482204926.

[6] Johan Andersson. A survey of multiobjective optimization in engineering design. Tech. rep. Linköping: Department of Mechanical Engineering, Linköping University. Sweden, 2000, p. 34. DOI: Li TH-IKP-R-1097.

[7] Autodesk. Additive Manufacturing and Design Software | Netfabb | Autodesk. URL: https: / / www . autodesk. com/products/net fabb/ overview (visited on 06/28/2017).

[8] Christiane Beyer and Dustin Figueroa. "Design and Analysis of Lattice Structures for Additive Manufacturing". In: Journal of Manufacturing Science and Engineering 138.12 (2016), p. 121014. ISSN: 1087-1357. DOI: $10.1115 / 1.4033957$. 
[9] H Bikas, P Stavropoulos, and G Chryssolouris. "Additive manufacturing methods and modelling approaches: a critical review". In: The International Journal of Advanced Manufacturing Technology 83.1 (2016), pp. 389-405. ISSN: 0268-3768. DOI: 10.1007 /s00170-015-7576-2.

[10] K Blake Perez. "Design Innovation with Additive Manufacturing (AM): An AM-centric Design Innovation Process". PhD thesis. Singapore University of Technology and Design, 2018, pp. 1-153.

[11] Lucienne T.M Blessing and Amaresh Chakrabarti. DRM, a Design Research Methodology. London: Springer, 2009.

[12] Alexandra Blösch-Paidosh and Kristina Shea. "Design Heuristics for Additive Manufacturing Validated Through a User Study1". In: Journal of Mechanical Design, Transactions of the ASME 141.4 (2019). ISSN: 10500472. DOI: 10.1115/1.4041051.

[13] Jorge D. Camba, Manuel Contero, and Pedro Company. "Parametric CAD modeling: An analysis of strategies for design reusability". In: CAD Computer Aided Design 74 (2016), pp. 18-31. ISSN: 00104485. DOI: $10.1016 / \mathrm{j} . \mathrm{cad} .2016 .01 .003$.

[14] P.W. Christensen and A. Klarbring. An Introduction to Structural Optimization. Solid Mechanics and Its Applications. Springer Netherlands, 2008. ISBN: 9781402086663.

[15] C. Werner Dankwort, Roland Weidlich, Birgit Guenther, and Joerg E. Blaurock. "Engineers' CAx education - It's not only CAD". In: $C A D$ Computer Aided Design (2004). ISSN: 00104485. DOI: $10.1016 / \mathrm{j}$. cad. 2004.02 .011$.

[16] Kalyanmoy Deb, Samir Agrawal, Amrit Pratap, and T. Meyarivan. "A Fast Elitist Non-dominated Sorting Genetic Algorithm for Multiobjective Optimization: NSGA-II". In: Parallel Problem Solving from Nature PPSN VI. Ed. by Marc Schoenauer, Kalyanmoy Deb, Günther Rudolph, Xin Yao, Evelyne Lutton, Juan Julian Merelo, and HansPaul Schwefel. Berlin, Heidelberg: Springer Berlin Heidelberg, 2000, pp. 849-858. ISBN: 978-3-540-45356-7.

[17] William E Frazier. "Metal additive manufacturing: A review". In: Journal of Materials Engineering and Performance 23.6 (2014), pp. 1917-1928. ISSN: 15441024. DOI: 10.1007/s11665-014-0958-z.

[18] Wei Gao, Yunbo Zhang, Devarajan Ramanujan, Karthik Ramani, Yong Chen, Christopher B Williams, Charlie C.L. Wang, Yung C Shin, Song Zhang, and Pablo D Zavattieri. "The status, challenges, and future of additive manufacturing in engineering". In: Computer-Aided Design 69 (2015), pp. 65-89. ISSN: 00104485. DOI: $10.1016 /$ j . cad. 2015 . 04 . 001. 
[19] Ian Gibson, David Rosen, and B. (Brent) Stucker. Additive manufacturing technologies : 3D printing, rapid prototyping, and direct digital manufacturing. 2nd ed. 20. 2015, p. 498. ISBN: 9781493921133.

[20] David E. Goldberg. Genetic Algorithms in Search, Optimization and Machine Learning. 1st. Boston, MA, USA: Addison-Wesley Longman Publishing Co., Inc., 1989. ISBN: 0201157675.

[21] Haijun Gong, Khalid Rafi, Hengfeng Gu, Thomas Starr, and Brent Stucker. "Analysis of defect generation in Ti-6Al-4V parts made using powder bed fusion additive manufacturing processes". In: Additive Manufacturing (2014). ISSN: 22148604. DOI: 10.1016 / j . addma . 2014.08 .002 .

[22] Xibing Gong, Ted Anderson, and Kevin Chou. "Review on PowderBased Electron Beam Additive Manufacturing Technology". In: Manufacturing Review 1 (2014), p. 12. DOI: 10.1115 / ISFA2012-7256.

[23] D D Gu, W Meiners, K Wissenbach, and R Poprawe. "Laser additive manufacturing of metallic components: materials, processes and mechanisms". In: International Materials Reviews 57.3 (May 2012), pp. 133164. ISSN: 0950-6608. DOI: $10.1179 / 1743280411$ Y . 0000000014.

[24] Sebastian Hällgren, Lars Pejryd, and Jens Ekengren. "3D Data Export for Additive Manufacturing - Improving Geometric Accuracy”. In: Procedia CIRP 50 (2016), pp. 518-523.

[25] Staffan Hansson. Den skapande människan : om människan och tekniken under 5000 år. Lund: Studentlitteratur, 2002. ISBN: 9144021488.

[26] A.A. Hopgood. Intelligent Systems for Engineers and Scientists. CRC Press, 2016. ISBN: 9781439865965.

[27] Robert Ian, Yong Se, Robert Ian Campbell, Haeseong Jee, Yong Se Kim, Robert Ian, and Yong Se. "Adding product value through additive manufacturing". In: Proceedings of the International Conference on Engineering Design, ICED 4 DS75-04.August (2013), pp. 259-268. ISSN: 22204334. DOI: $10.1080 / 0042311$ YYXXXXXXXX.

[28] ISO/ASTM. SS-EN ISO/ASTM 52900:2017. 2017.

[29] ISO/TC 261. ISO/ASTM 52915:2016. Tech. rep. ISO/ASTM, 2016, p. 26. URL: https://www.iso.org/standard/67472.html.

[30] Jingchao Jiang, Xun $\mathrm{Xu}$, and Jonathan Stringer. "Support Structures for Additive Manufacturing: A Review". In: Journal of Manufacturing and Materials Processing 2.4 (2018). ISSN: 2504-4494. DOI: 10 . 3390 / jmmp2040064.

[31] Joel Johansson. "Design Automation Systems for Production Preparation - Applied on the Rotary Draw Bending Process". PhD thesis. Chalmers University of Technology, 2008, pp. 1-75. DOI: 1652-9243. 
[32] M. Kahlin, H. Ansell, and J. J. Moverare. "Fatigue behaviour of additive manufactured Ti6Al4V, with as-built surfaces, exposed to variable amplitude loading". In: International Journal of Fatigue 103 (2017), pp. 353-362. ISSN: 01421123. DOI: 10 . $1016 /$ j. ijfatigue. 2017 . 06.023.

[33] A. Karniel and Y. Reich. Managing the Dynamics of New Product Development Processes: A New Product Lifecycle Management Paradigm. Managing the Dynamics of New Product Development Processes: A New Product Lifecycle Management Paradigm. Springer London, 2011. ISBN: 9780857295705.

[34] Christoph Klahn, Bastian Leutenecker, and Mirko Meboldt. "Design for additive manufacturing - Supporting the substitution of components in series products". In: Procedia CIRP 21 (2014), pp. 138-143. ISSN: 22128271. DOI: 10.1016/j.procir.2014.03.145.

[35] Christoph Klahn, Bastian Leutenecker, and Mirko Meboldt. "Design strategies for the process of additive manufacturing". In: Procedia CIRP 36 (2015), pp. 230-235. ISSN: 22128271. DOI: 10 . $1016 / \mathrm{j}$. procir. 2015.01 .082$.

[36] S Lammers, J Tominski, S Magerkohl, T Künneke, T Lieneke, and D Zimmer. "Design Guidelines for a Software-Supported Adaptation of Additively Manufactured Components with Regard to a Robust Production". In: Solid Freeform Fabrication 2018: Proceedngs of the 29th Annual International Solid Freeform Fabrication Symposium - An Additive Manufacturing Conference. Texas, Austin: Laboratory for Freeform Fabrication and University of Texas at Austin, 2018, pp. 527-540.

[37] LiU Formula Student. Lil Formula Student. 2017. URL: http : / / www . liuformulastudent. se/ (visited on 09/27/2017).

[38] Jikai Liu, Andrew T Gaynor, Shikui Chen, Zhan Kang, Krishnan Suresh, Akihiro Takezawa, Lei Li, Junji Kato, Jinyuan Tang, Charlie C L Wang, Lin Cheng, Xuan Liang, and Albert. C To. "Current and future trends in topology optimization for additive manufacturing". In: Structural and Multidisciplinary Optimization 57.6 (June 2018), pp. 24572483. ISSN: 1615-1488. DOI: 10.1007 /s $00158-018-1994-3$.

[39] Bin maidin. "Development of a design feature database to support design for additive manufacturing". In: Assembly Automation, Vol. 32 Iss: 3, pp.235 - 244 (2012). ISSN: 0144-5154. DOI: 10 . 1108 / 01445151211244375.

[40] Materlise NV. Materialise I 3D Printing Innovators. URL: http : / / www . materialise.com/en (visited on 06/28/2017). 
[41] MSC Software. Simulating Additive Manufacturing with Simufact Additive I simufact. URL: https : / / www. simufact. com / simufact additive.html (visited on 06/28/2017).

[42] Lawrence E. Murr, Sara M. Gaytan, Diana A. Ramirez, Edwin Martinez, Jennifer Hernandez, Krista N. Amato, Patrick W. Shindo, Francisco R. Medina, and Ryan B. Wicker. "Metal Fabrication by Additive Manufacturing Using Laser and Electron Beam Melting Technologies". In: Journal of Materials Science Technology 28.1 (2012), pp. 1-14. ISSN: 1005-0302. DOI: https : / / doi . org/10.1016/S1005-0302 (12) 60016-4.

[43] Lawrence E. Murr and Shujun Li. "Electron-beam additive manufacturing of high-temperature metals". In: MRS Bulletin 41.10 (2016), pp. 752-757. DOI: $10.1557 / \mathrm{mrs} .2016 .210$.

[44] Myriam Orquéra, Sébastien Campocasso, and Dominique Millet. “Design for Additive Manufacturing Method for a Mechanical System Downsizing". In: Procedia CIRP. Vol. 60. The Author(s), 2017, pp. 223228. DOI: $10.1016 / j$.procir.2017.02.011.

[45] P.Y. Papalambros and D.J. Wilde. Principles of Optimal Design: Modeling and Computation. Principles of Optimal Design: Modeling and Computation. Cambridge University Press, 2000. ISBN: 9780521627276.

[46] Remi Ponche, Olivier Kerbrat, Pascal Mognol, and Jean Yves Hascoet. "A novel methodology of design for Additive Manufacturing applied to Additive Laser Manufacturing process". In: Robotics and ComputerIntegrated Manufacturing 30.4 (2014), pp. 389-398. ISSN: 07365845. DOI: $10.1016 / j . r c i m .2013 .12 .001$.

[47] Gianfranco La Rocca. "Knowledge based engineering: Between AI and CAD. Review of a language based technology to support engineering design". In: Advanced Engineering Informatics 26.2 (Apr. 2012), pp. 159179. ISSN: 14740346. DOI: $10.1016 / \mathrm{j}$.aei.2012.02.002.

[48] Hugo Rodrigue and Mickaël Rivette. "An Assembly-Level Design for Additive Manufacturing Methodology". In: IDMME - Virtual Concept (2010), pp. 1-9. DOI: $10.1007 / 978-2-8178-0169-8$.

[49] David W. Rosen. "Research supporting principles for design for additive manufacturing". In: Virtual and Physical Prototyping 9.4 (2014), pp. 225-232. ISSN: 1745-2759. DOI: 10 . $1080 / 17452759$. 2014 . 951530.

[50] V. Salehi-Douzloo. An Integrated Approach to Parametric Associative Design for Powertrain Components on the Automotive Industry. University of Bath, 2012. 
[51] Konstantinos Salonitis and Saeed Al Zarban. "Redesign optimization for manufacturing using additive layer techniques". In: Procedia CIRP 36 (2015), pp. 193-198. ISSN: 22128271. DOI: 10 . 1016 / j p procir. 2015.01 .058$.

[52] Siemens AG. NX Hybrid Additive Manufacturing: Siemens PLM Software. 2017. URL: https: / / www • plm . automation. siemens. com/en / products/nx/for-manufacturing/cam/hybrid-additivemanufacturing. shtml (visited on 11/06/2017).

[53] Simplify3D. 3D Printing Software I Simplify3D. URL: https : / / www . simplify3d.com/ (visited on 06/28/2017).

[54] Timothy W Simpson. Trade-offs with AM. 2017.

[55] Wojciech Skarka. "Application of MOKA methodology in generative model creation using CATIA". In: Engineering Applications of Artificial Intelligence 20.5 (2007), pp. 677-690. ISSN: 09521976. DOI: 10.1016 / j . engappai.2006.11.019.

[56] Jaroslaw Sobieszczanski-Sobieski, Alan Morris, and Michel van Tooren. Multidisciplinary design optimization supported by knowledge based engineering. Chichester, West Sussex: Wiley Blackwell, 2015. ISBN: 9781118492123.

[57] Svjetlana Stekovic. AddMan. 2019. URL: https : / / sites . google. com/site/addmanproject/home (visited on 07/28/0219).

[58] Y Tang, G Dong, Q Zhou, and Y F Zhao. "Lattice Structure Design and Optimization With Additive Manufacturing Constraints". In: IEEE Transactions on Automation Science and Engineering 15.4 (2018), pp. 15461562. ISSN: 1545-5955 VO - 15. DOI: $10.1109 /$ TASE . 2017.2685643.

[59] Yunlong Tang, Aidan Kurtz, and Yaoyao Fiona Zhao. “Bidirectional Evolutionary Structural Optimization (BESO) based design method for lattice structure to be fabricated by additive manufacturing". In: Computer-Aided Design 69 (2015), pp. 91-101. ISSN: 0010-4485. DOI: https://doi.org/10.1016/j.cad.2015.06.001.

[60] Daniel Thomas. "The Development of Design Rules for Selective Laser Melting". Ph.D thesis. University of Wales, 2009.

[61] Mary Kathryn Thompson, Giovanni Moroni, Tom Vaneker, Georges Fadel, R. Ian Campbell, Ian Gibson, Alain Bernard, Joachim Schulz, Patricia Graf, Bhrigu Ahuja, and Filomeno Martina. "Design for Additive Manufacturing: Trends, opportunities, considerations, and constraints". In: CIRP Annals - Manufacturing Technology 65.2 (2016), pp. 737-760. ISSN: 17260604. DOI: $10.1016 /$ j. cirp. 2016.05 .004$. arXiv: arXiv:1011.1669v3. 
[62] Wim J.C. Verhagen, Pablo Bermell-Garcia, Reinier E.C. Van Dijk, and Richard Curran. "A critical review of Knowledge-Based Engineering: An identification of research challenges". In: Advanced Engineering Informatics 26.1 (2012), pp. 5-15. ISSN: 14740346. DOI: $10.1016 / j$. aei. 2011.06 .004$.

[63] Xun Xu. "Integrating advanced computer-aided design, manufacturing, and numerical control: principles and implementations". In: International Journal of Production Research 49.11 (2011), pp. 3425-3426. ISSN: 0020-7543. DOI: $10.1080 / 00207543.2010 .501547$.

[64] Sheng Yang and Yaoyao Fiona Zhao. "Additive ManufacturingEnabled Part Count Reduction: A Lifecycle Perspective". In: Journal of Mechanical Design 140.3 (Jan. 2018), pp. 31702-31712. ISSN: 1050-0472.

[65] Tomás Zegard and Glaucio H. Paulino. "Bridging topology optimization and additive manufacturing". In: Structural and Multidisciplinary Optimization 53.1 (2016), pp. 175-192. ISSN: 16151488. DOI: 10 . 1007 / s00158-015-1274-4.

[66] Pu Zhang, Jakub Toman, Yiqi Yu, Emre Biyikli, Mesut Kirca, Markus Chmielus, and Albert C. To. "Efficient Design-Optimization of Variable-Density Hexagonal Cellular Structure by Additive Manufacturing: Theory and Validation". In: Journal of Manufacturing Science and Engineering 137.April (2014), p. 021004. ISSN: 1087-1357. DOI: $10.1115 / 1.4028724$. 



\section{Papers}

The papers associated with this thesis have been removed for copyright reasons. For more details about these see:

http://urn.kb.se/resolve?urn=urn:nbn:se:liu:diva-160888 


\section{FACULTY OF SCIENCE AND ENGINEERING}

Linköping Studies in Science and Technology, Thesis No. 1854, 2019

Department of management and engineering

Linköping University

SE-581 83 Linköping, Sweden

www.liu.se 